Supplementary Information (ESI)

\title{
Synthesis and Characterization of a Leucine-based Block Co-polypeptide: The Effect of the Leucine Zipper on Self- Assembly
}

\author{
Brooke E. Barnes, ${ }^{*}$ Taylor A. Jenkins, ${ }^{*}$ Lauren M. Stein, ${ }^{*}$ Robert T. Mathers ${ }^{\ddagger}$, Masita \\ Wicaksana, ${ }^{\dagger}$ Melissa A. Pasquinelli, ${ }^{\dagger \dagger}$ Daniel A. Savin ${ }^{*}$ \\ * George \& Josephine Butler Polymer Research Laboratory, Center for Macromolecular Science \& Engineering, \\ Department of Chemistry, University of Florida, Gainesville, FL 32611, USA. \\ ${ }^{\ddagger}$ Department of Chemistry, Pennsylvania State University, New Kensington, PA 15068, USA. \\ ${ }^{\dagger}$ William G. Enloe Magnet High School, 128 Claredon Cresent, Rayleigh, NC 27610, USA. \\ ${ }^{t h}$ Fiber and Polymer Science Program, North Carolina State University, Rayleigh, NC 27695, USA.
}

\section{Corresponding Author:}

*savin@chem.ufl.edu 


\section{Table of Contents}

\section{Synthesis and Characterization Data}

$\begin{array}{ll}\text { General synthesis of NCAs } & \text { S3 }\end{array}$

$\begin{array}{ll}\text { Synthesis of polypeptide triblock } & \text { S6 }\end{array}$

$\begin{array}{ll}\text { Deprotection of polypeptide triblock } & \mathrm{S} 12\end{array}$

$\begin{array}{lr}\text { Gel Permeation Chromatography } & \text { S12 }\end{array}$

$\begin{array}{lr}\text { Calculation of Hildebrand Solubility Parameters } & \text { S13 }\end{array}$

$\begin{array}{lr}\text { DPD Computational Models } & \text { S14 }\end{array}$

\section{Light scattering and Circular Dichroism Data}

$\begin{array}{lr}\text { THF Co-Solvent } & \text { S18 }\end{array}$

$\begin{array}{lr}\text { THF Solvent switch } & \text { S19 }\end{array}$

$\begin{array}{lr}\text { TFA Co-Solvent } & \text { S20 }\end{array}$

$\begin{array}{lr}\text { TFA Solvent switch } & \text { S22 }\end{array}$

$\begin{array}{lr}\text { DMF Co-Solvent } & \text { S23 }\end{array}$

$\begin{array}{lr}\text { DMF Solvent Switch } & \text { S24 }\end{array}$

$\begin{array}{lr}\text { Dioxane Co-Solvent } & \text { S26 }\end{array}$

$\begin{array}{lr}\text { Dioxane Solvent Switch } & \text { S27 }\end{array}$

$\begin{array}{lr}\text { DMSO Co-Solvent } & \text { S29 }\end{array}$

$\begin{array}{lr}\text { DMSO Solvent Switch } & \text { S30 }\end{array}$

$\begin{array}{ll}\text { pH } 2 \text { Buffer } & \text { S31 }\end{array}$

$\begin{array}{lr}\text { Urea Solvent Switch } & \text { S33 }\end{array}$

$\begin{array}{lr}\text { TFA Progression Study } & \text { S34 }\end{array}$

$\begin{array}{lr}\text { Effect of TFE on Assembly Size } & \text { S35 }\end{array}$

TFA Refractive Index Standard Curve $\quad$ S35

$\begin{array}{lr}P E O_{113}-P L V_{48}-P K_{40} T F A & \text { Solvent Switch }\end{array}$

$\begin{array}{ll}\text { References } & \text { S37 }\end{array}$ 
Synthesis and Characterization Data

Scheme S1. Synthesis of N-carboxyanhydrides (NCAs)
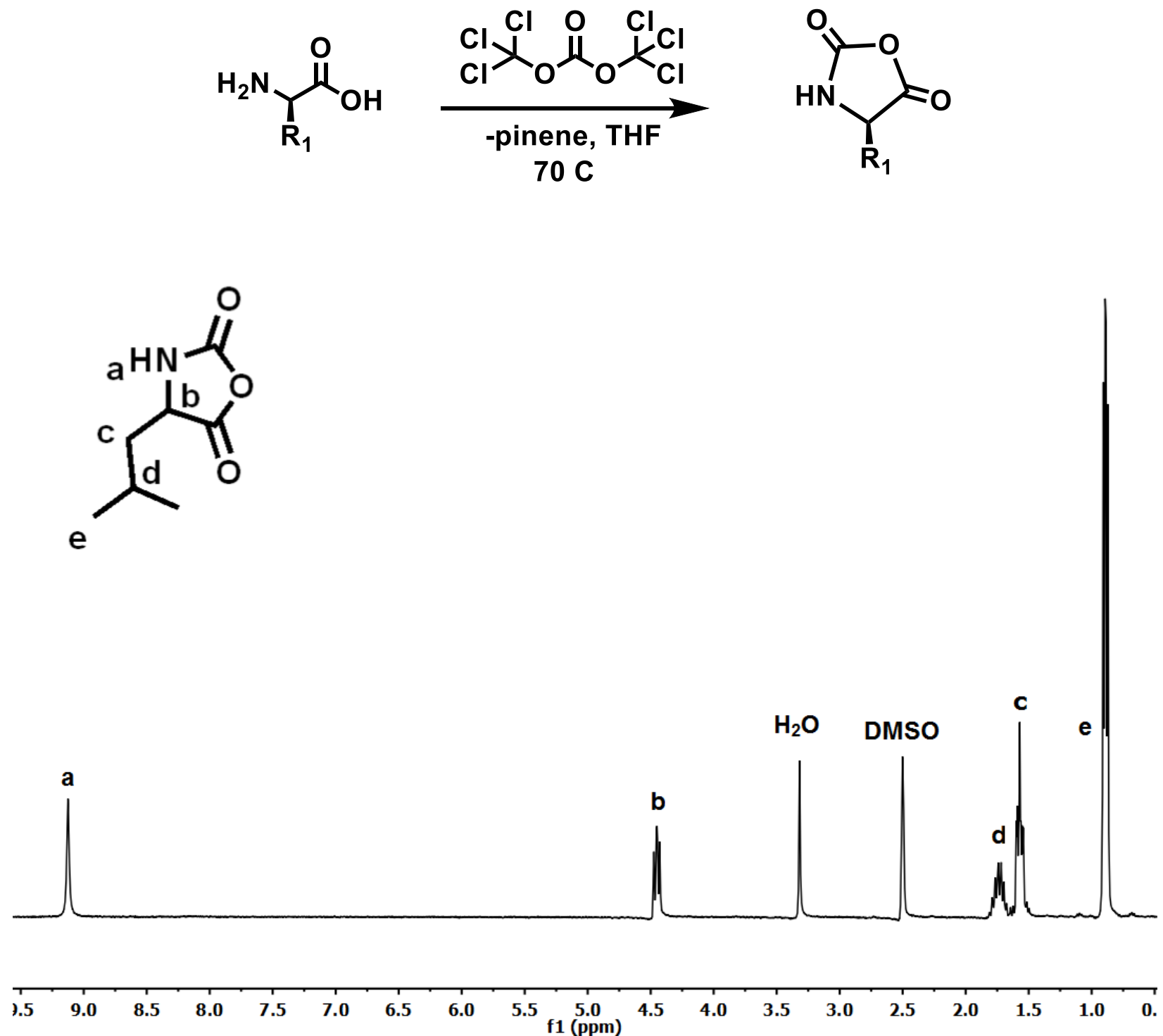

Figure S1. ${ }^{1} \mathrm{H}$ NMR spectrum of leucine NCA in DMSO- $d_{6}$. 

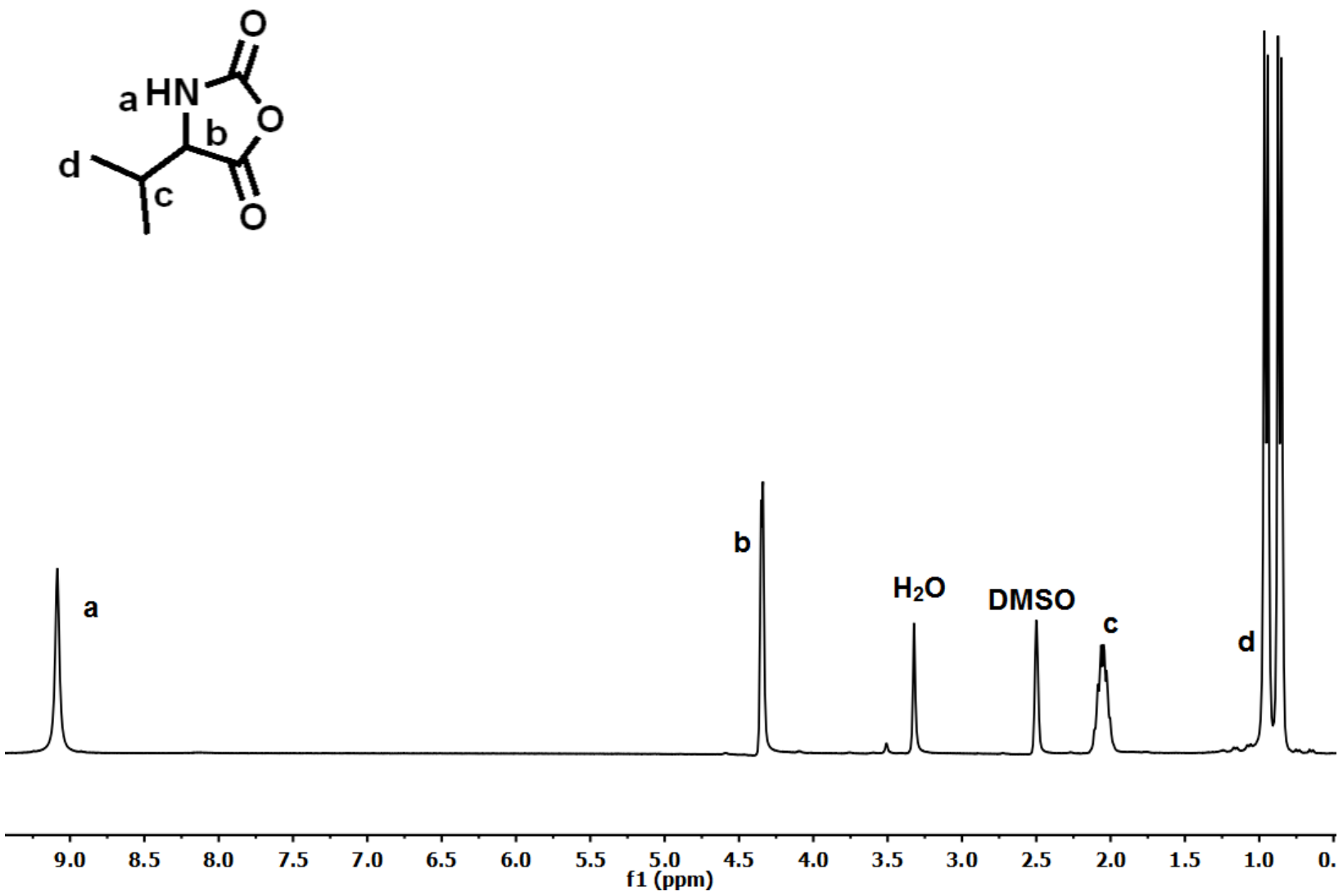

Figure S2. ${ }^{1} \mathrm{H}$ NMR spectrum of valine NCA in DMSO- $d_{6}$. 

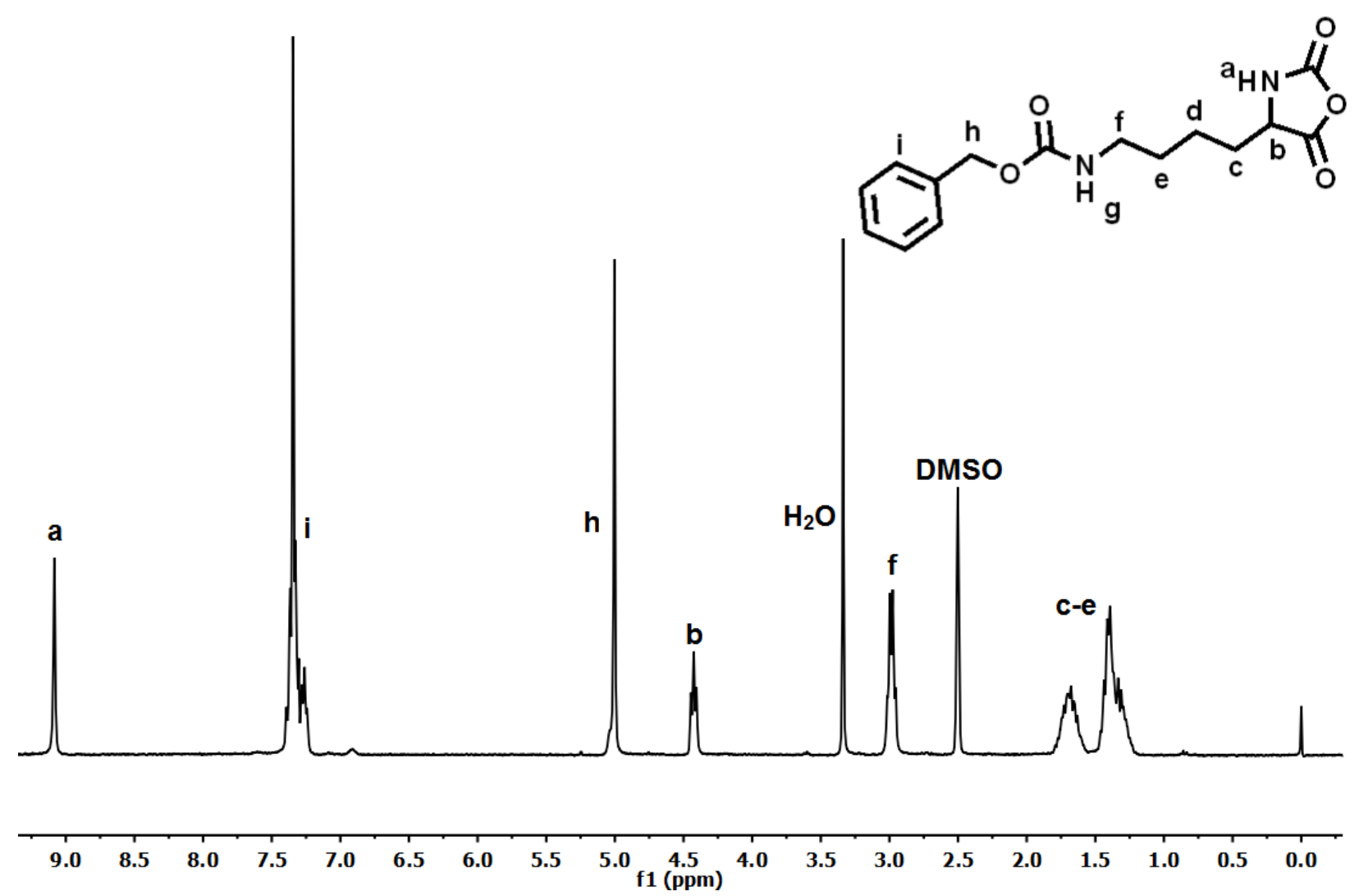

Figure S3. ${ }^{1} \mathrm{H}$ NMR spectrum of $\mathrm{N}^{\varepsilon}$-carboxybenzyl-lysine NCA in DMSO- $d_{6}$. 
Scheme S2. General synthesis of polypeptide triblocks
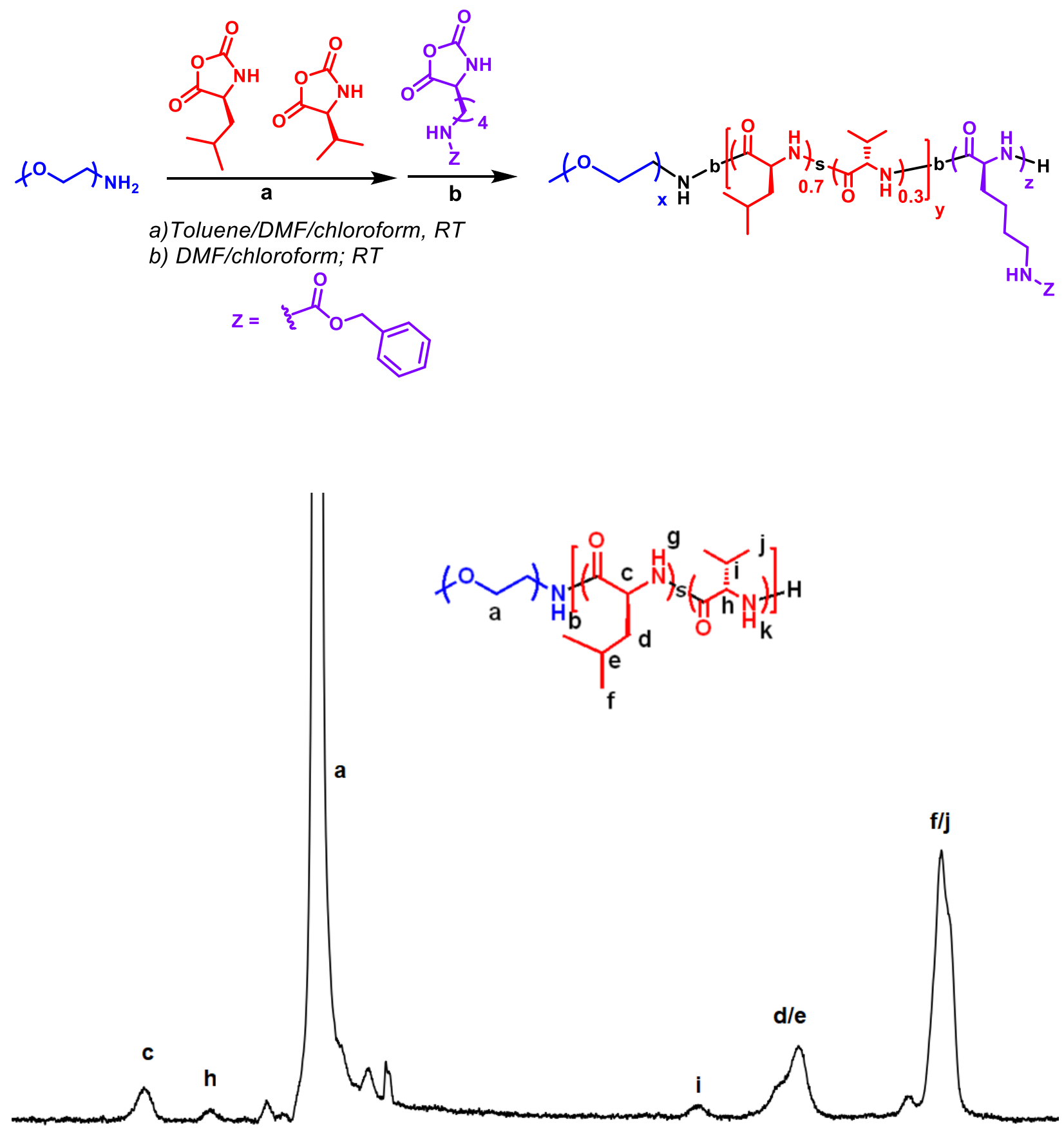

$\begin{array}{llllllllllllllllllllllll}5.2 & 5.0 & 4.8 & 4.6 & 4.4 & 4.2 & 4.0 & 3.8 & 3.6 & 3.4 & 3.2 & \begin{array}{l}3.0 \\ \text { fi }(\mathrm{ppm})\end{array} & 2.6 & 2.4 & 2.2 & 2.0 & 1.8 & 1.6 & 1.4 & 1.2 & 1.0 & 0.8 & 0.6\end{array}$

Figure S4. ${ }^{1} \mathrm{H}$ NMR spectrum of $\mathrm{PEO}_{113}-\mathrm{PLV}_{6}$ in TFA- $d$. The degree of polymerization of the leucine and valine blocks can be determined from peaks at 4.8 and 4.4 ppm respectively. Using the PEO peak (a) at $3.9 \mathrm{ppm}$ as a reference, leucine (c) integrates to 5 and valine (h) integrates to 1 . 

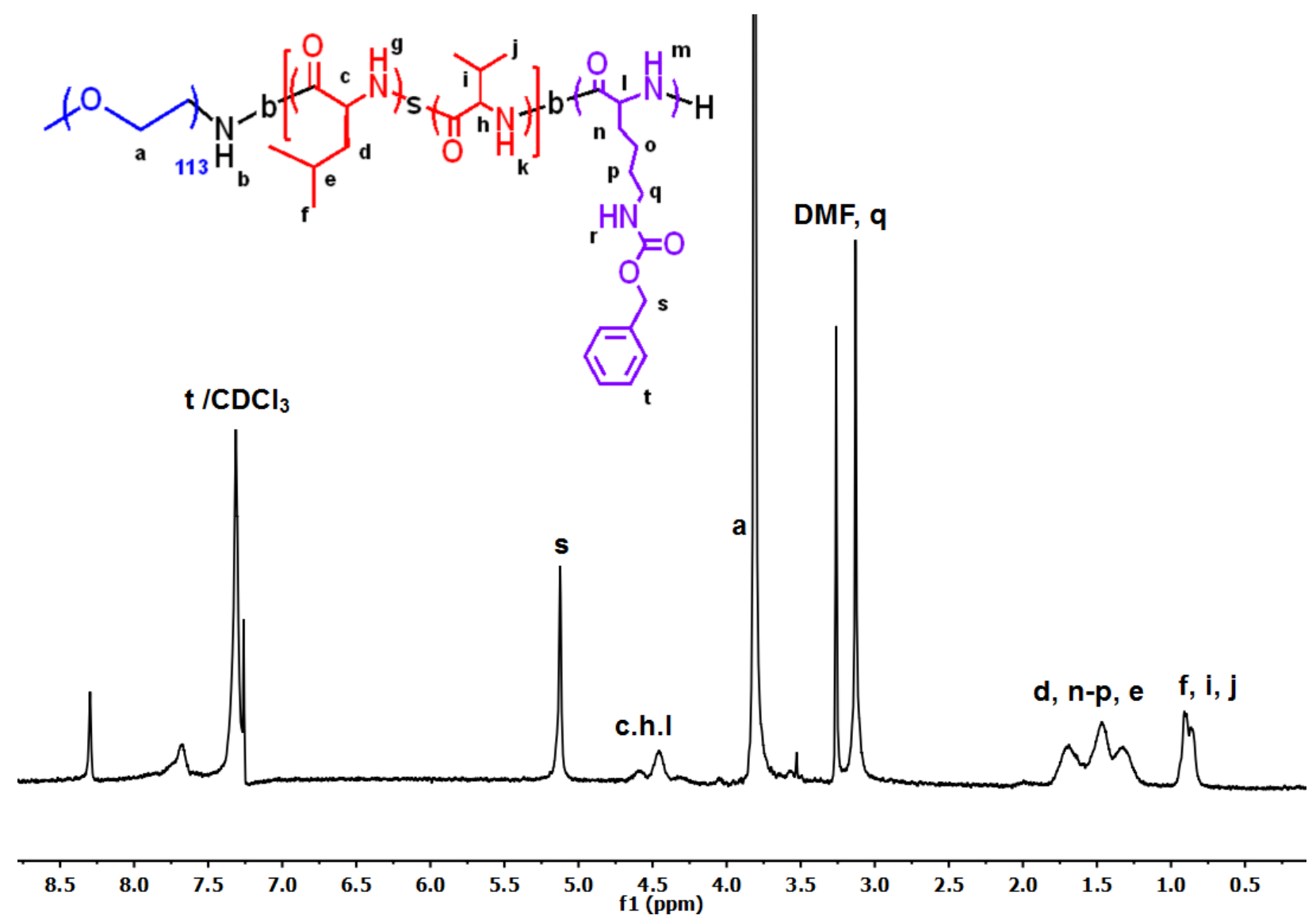

Figure S5. ${ }^{1} \mathrm{H}$ NMR spectrum of $\mathrm{PEO}_{113}-\mathrm{PLV}_{6}-\mathrm{PK}_{30}$ in TFA- $d$. The degree of polymerization of the lysine block can be determined from the peak at $4.46 \mathrm{ppm}$ (1). Using the PEO peak (a) at 3.8 ppm as a reference, the lysine peak (1) integrates to 30 . 


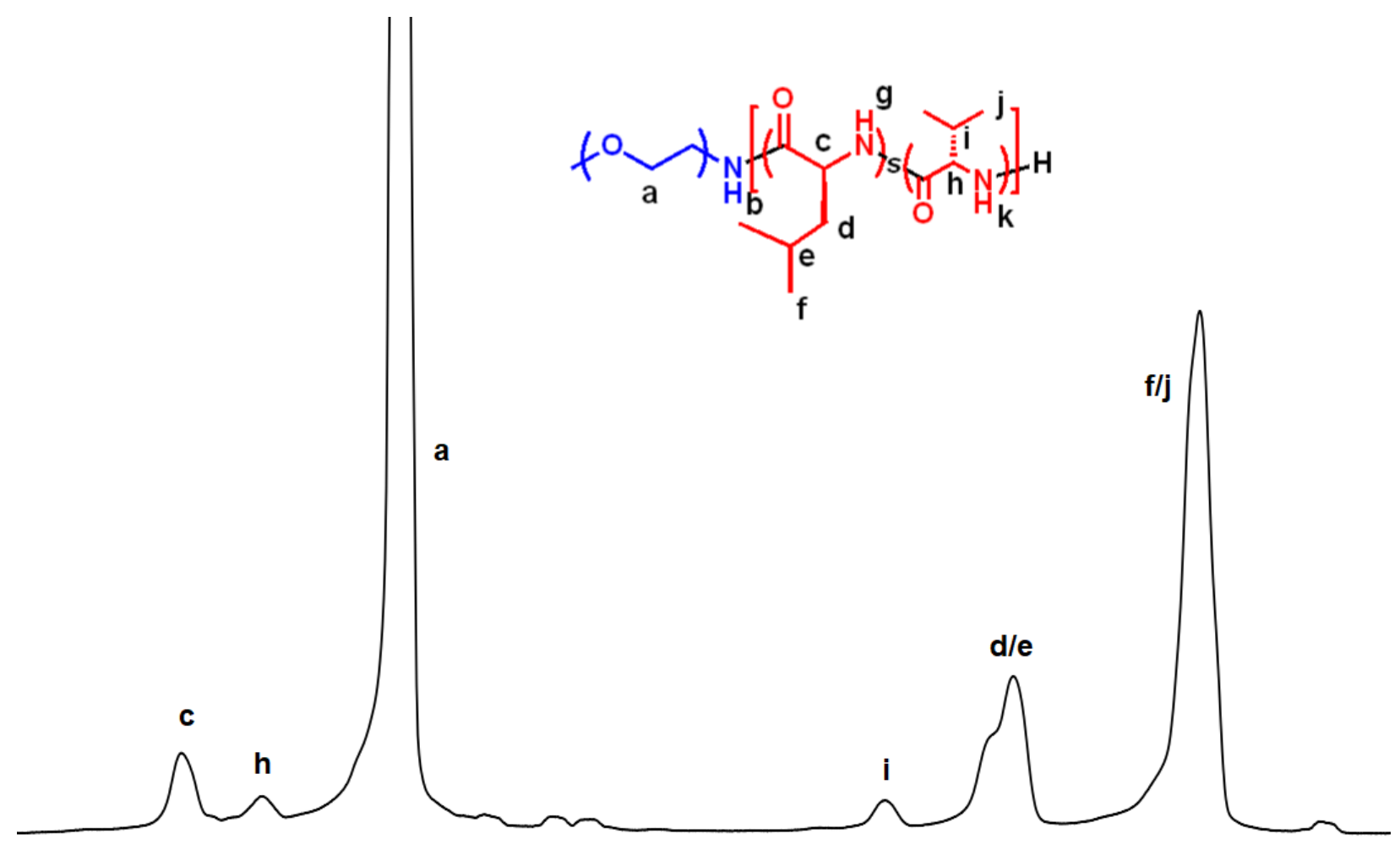

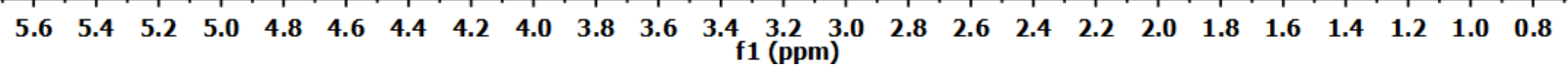

Figure S6. ${ }^{1} \mathrm{H}$ NMR spectrum of $\mathrm{PEO}_{113}-\mathrm{PLV}_{48}$ in TFA-d. The degree of polymerization of the leucine and valine blocks can be determined from peaks at 4.8 and $4.4 \mathrm{ppm}$ respectively. Using the PEO peak (a) at $3.9 \mathrm{ppm}$ as a reference, leucine (c) integrates to 32 and valine (h) integrates to 16 . 

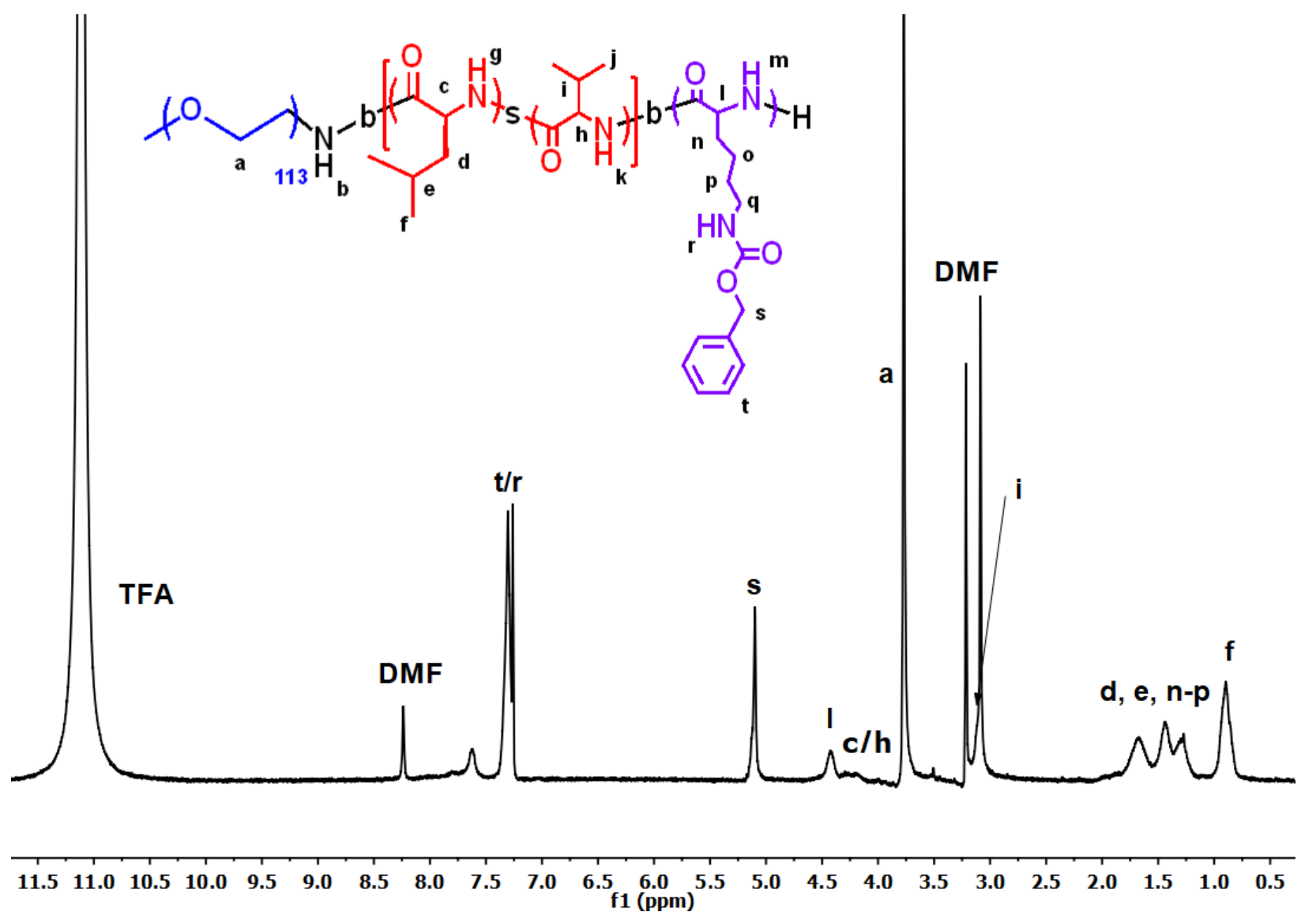

Figure S7. ${ }^{1} \mathrm{H}$ NMR spectrum of $\mathrm{PEO}_{113}-\mathrm{PLV}_{48}-\mathrm{PK}_{40}$ in TFA- $d$. The degree of polymerization of the lysine block can be determined from the peak at 4.4 ppm (1). Using the PEO peak (a) at 3.8 ppm as a reference, the lysine peak (1) integrates to 40 . 

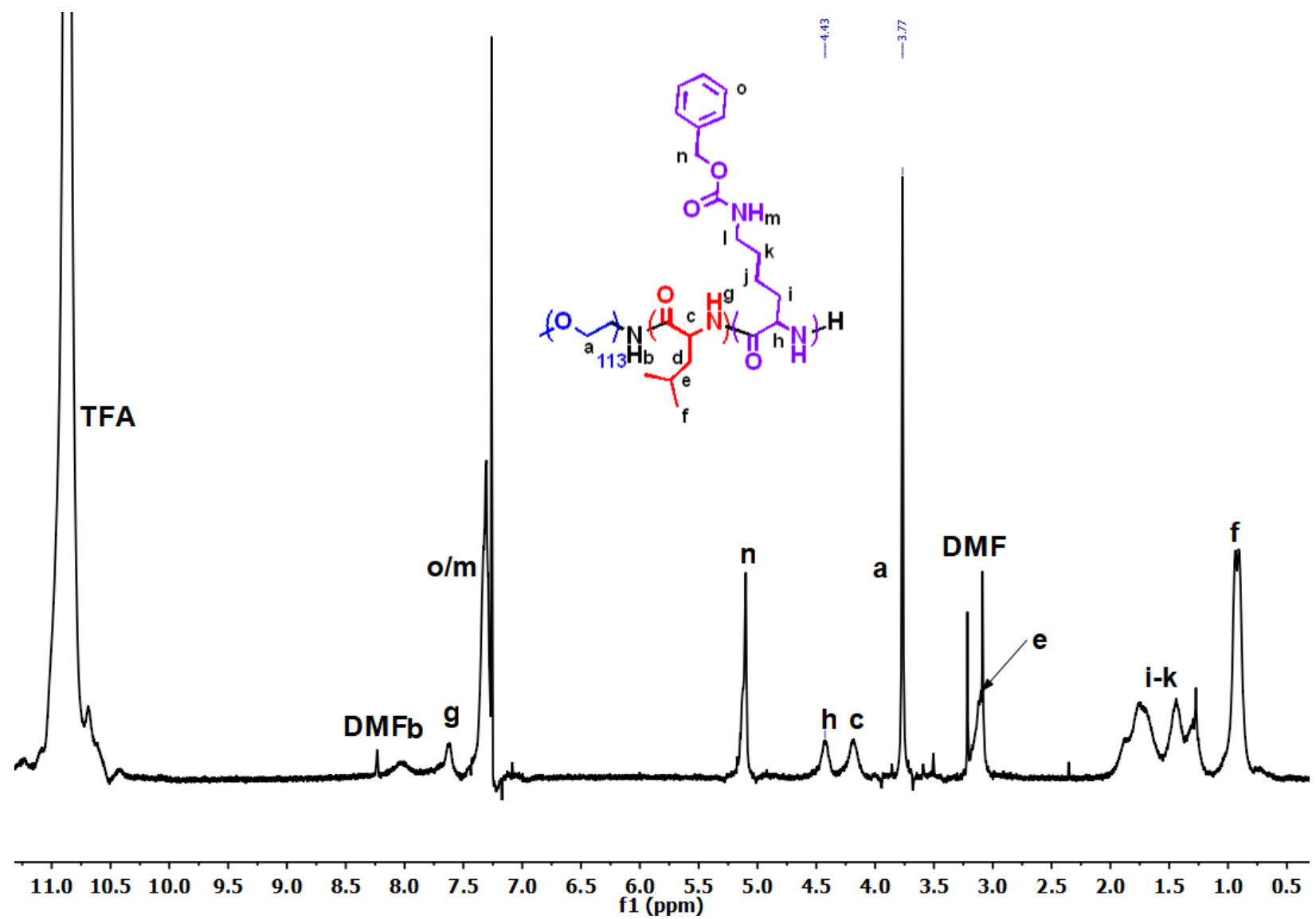

Figure S8. ${ }^{1} \mathrm{H}$ NMR spectrum of $\mathrm{PEO}_{45}-\mathrm{PL}_{71}-\mathrm{PK}_{62}$ in $\mathrm{CDCl}_{3} / 15 \mathrm{v} / \mathrm{v} \%$ TFA. The degree of polymerization of the lysine block can be determined from the peak at $4.43 \mathrm{ppm}(\mathrm{h})$. Using the PEO peak (a) at $3.8 \mathrm{ppm}$ as a reference, the leucine peak (c) integrated to 71 and lysine peak (h) integrates to 62 . 


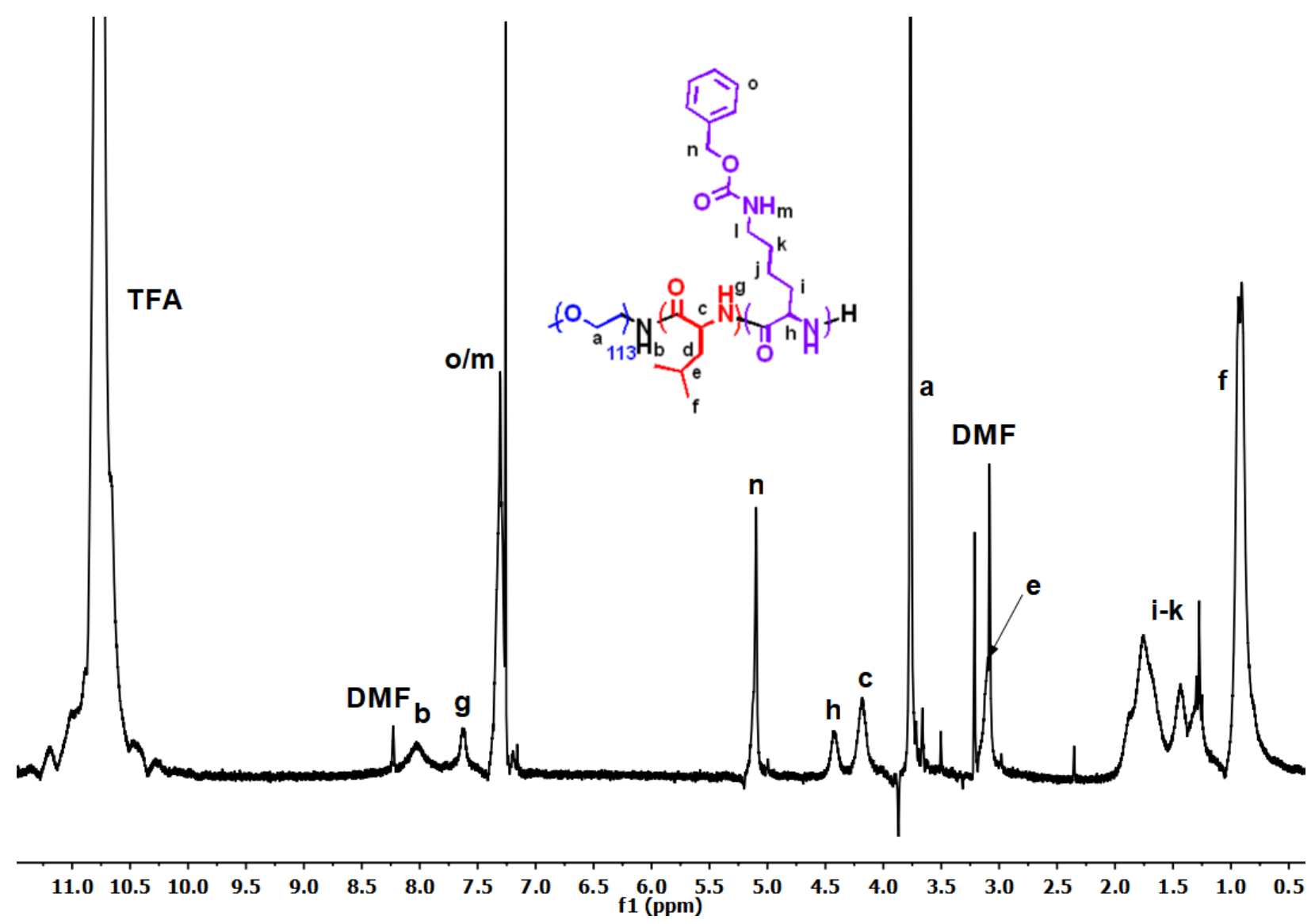

Figure S9. ${ }^{1} \mathrm{H}$ NMR spectrum of $\mathrm{PEO}_{45}-\mathrm{PL}_{71}-\mathrm{PK}_{30}$ in $\mathrm{CDCl}_{3} / 15 \mathrm{v} / \mathrm{v} \%$ TFA. The degree of polymerization of the lysine block can be determined from the peak at $4.43 \mathrm{ppm}(\mathrm{h})$. Using the PEO peak (a) at $3.8 \mathrm{ppm}$ as a reference, the leucine peak (c) integrated to 71 and lysine peak (h) integrates to 30 . 
Scheme S3. Deprotection of poly(lysine) block
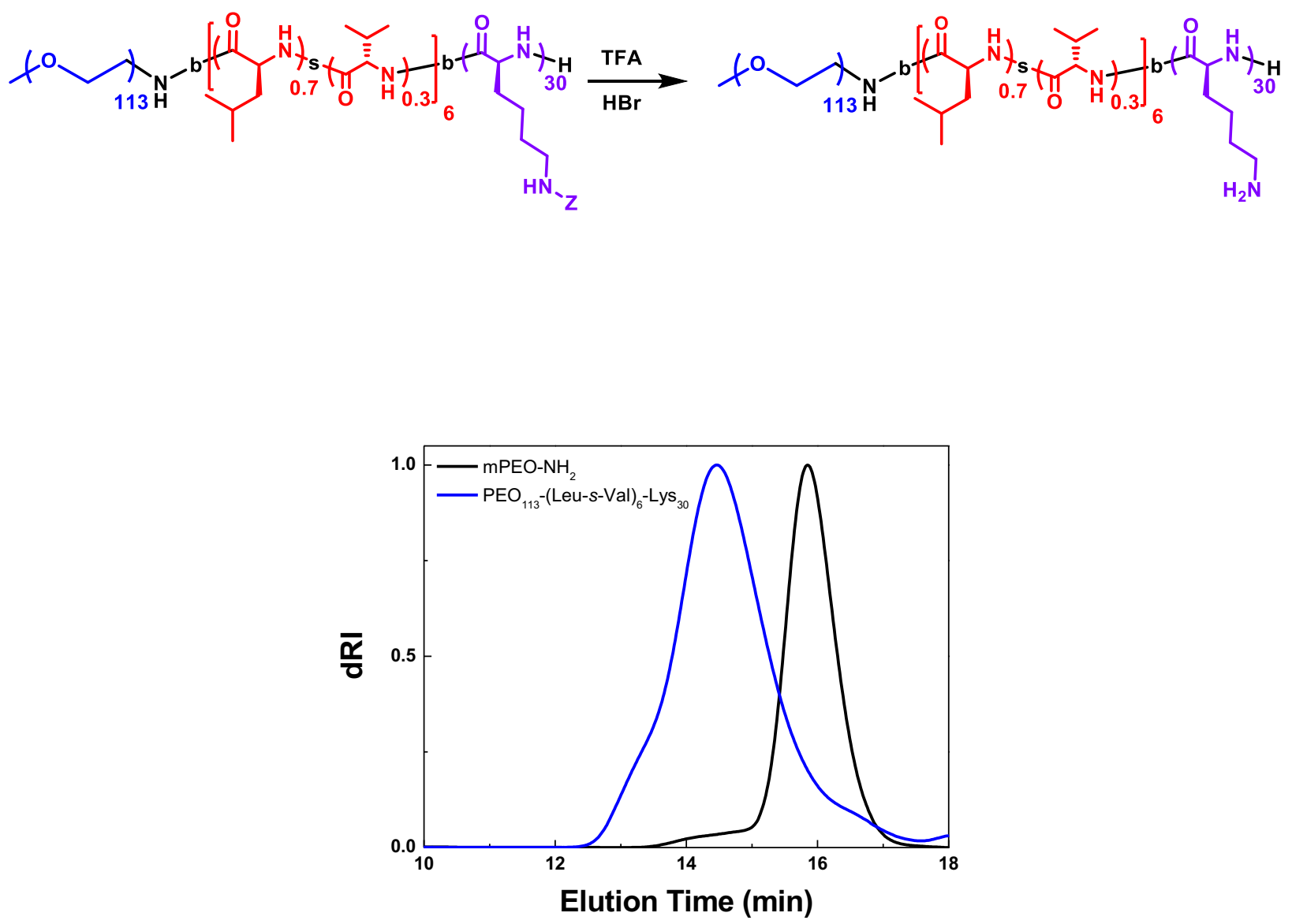

Figure S10. GPC dRI trace of $\mathrm{mPEO}_{113}-\mathrm{NH}_{2}$ macroinitiator (black), and $\mathrm{PEO}_{113}-\mathrm{PLV}_{6}-\mathrm{PK}(\mathrm{Z})_{30}$ triblock (blue).

Table S1. Polymer number average molecular weight $(M \mathrm{n})$, weight average molecular weight $\left(M_{\mathrm{w}}\right)$ and dispersity $(Đ)$ calculated from GPC results.

\begin{tabular}{|c|c|c|c|}
\hline Polymer & $\left.\boldsymbol{M}_{\mathbf{n}} \mathbf{( g / m o l}\right)$ & $\boldsymbol{M}_{\mathbf{w}}(\mathbf{g} / \mathbf{m o l})$ & Đ \\
\hline mPEO $_{\mathbf{1 1 3}}-\mathbf{N H}_{\mathbf{2}}$ & 5,809 & 6,025 & 1.04 \\
\hline PEO $\left._{\mathbf{1 1 3}} \mathbf{P L V}_{\mathbf{6}}-\mathbf{P K}_{\mathbf{3 0}} \mathbf{Z}\right)$ & 22,240 & 28,170 & 1.27 \\
\hline
\end{tabular}




\section{Calculation of Hildebrand Solubility Parameters ( $\delta$ )}

Molecular Models: A series of oligomer models were constructed in Materials Studio 2018 with the Build Polymers function. For PEO, the oligomers ranged from 10-mer to 40-mer and contained methyl and hydroxyl end groups. Construction of oligomers of leucine, lysine, and valine contained $\mathrm{N}$-methyl and proton end groups. Based on the block sizes in the triblock copolymer, the oligomers of leucine (4 to 10-mers), lysine (4 to 16-mers), and valine (4 to 10mers) were chosen accordingly.

Molecular Dynamics (MD) Simulation: Calculation of $\delta$ was accomplished with the Forcite Module of Materials Studio 2018. The method for minimizing the energy of oligomers involved adaptation of established methods., ${ }^{1,2}$ This MD strategy (Scheme S4) involved constructing a polymer chain, minimizing energy of a single polymer chain through Geometry Optimization, packing a cubic cell with polymer chains, minimizing energy of the cell through Geometry Optimization, annealing the cell with multiple heating and cooling cycles under constant volume conditions (NVT), compression and expansion cycles to find the correct density under NPT conditions, and calculation of $\delta$.

Initially, a single polymer chain composed of $n$-monomer units underwent an energy minimization procedure using the Forcite module in Materials Studio 2018. This Geometry Optimization procedure typically involved 2,000-10,000 steps with a Smart minimization algorithm that chooses the best minimization methods, like conjugate gradient or steepest descent, depending on the system. The procedure for optimizing this single chain employed a COMPASS II force field in the Forcite module. ${ }^{3-5}$ Optimization continued until meeting a $1.0 \times 10^{-4} \mathrm{kcal} / \mathrm{mol}$ energy convergence, a $0.005 \mathrm{kcal} / \mathrm{mol} / \AA$ force convergence, and a $5.0 \times 10^{-5} \AA$ displacement convergence criteria.

After minimizing the energy of a single chain, a cubic box ( $3 \mathrm{~nm} \times 3 \mathrm{~nm} \times 3 \mathrm{~nm})$ with periodic boundary conditions was packed with polymer chains using the Amorphous Cell module. These box dimensions represent typical sizes. ${ }^{1}$ In the case of PEO, the Amorphous Cell consisted of 21 PEO chains, each with 20 monomer units. For octamers of polyleucine, the cubic box ( $3 \mathrm{~nm}$ x $3 \mathrm{~nm} \times 3 \mathrm{~nm}$ ) with periodic boundary conditions contained 18 oligomers. During packing of the Amorphous Cell, the density ramped from $0.6 \mathrm{~g} / \mathrm{mL}$ to the $1.1 \mathrm{~g} / \mathrm{mL}$ to minimize voids. Then, the cubic cell was subjected to a similar Geometry Optimization procedure as the single polymer chain. Afterwards, 5 annealing cycles were conducted under constant volume conditions (i.e. NVT) with a sinusoidal temperature profile by ramping the temperature from $300 \mathrm{~K}$ to $700 \mathrm{~K}$ in 100K increments. Choice of annealing temperatures and NVT ensemble are based on literature values. Next, the density of the annealed cell was refined through a MD simulation with NPT ensemble for 300 ps with a 1 fs time step for a total of 300,000 steps. The non-bonded cutoff was $10 \AA$. Every 5000 steps, a frame was exported to provide 60 frames for analysis. After discarding frames 1-30, frames 31-60 were used to determine $\delta$. Finally, the Cohesive Energy Density function of Forcite was employed to calculate the $\delta$ value for each frame. 
Calculation of Hildebrand Solubility Parameters for (TFA) was conducted with the Forcite Module of Materials Studio 2018. Initially, an Amorphous Cell was packed with 200 TFA molecules using known density values. ${ }^{32}$ The cell underwent a Geometry Optimization procedure until meeting a $1.0 \times 10^{-4} \mathrm{kcal} / \mathrm{mol}$ energy convergence, a $0.005 \mathrm{kcal} / \mathrm{mol} / \AA$ force convergence, and a $5.0 \times 10^{-5} \AA$ displacement convergence criteria. Then, the cell was subjected to 5 annealing cycles under constant volume conditions (i.e. NVT) with a sinusoidal temperature ramp from $300 \mathrm{~K}$ to $500 \mathrm{~K}$. Afterwards, further equilibration involved a MD simulation with NVT ensemble for 300 ps with a 1 fs time step and non-bonded cutoff of $12 \AA$. Every 5000 steps, a frame was exported to provide 60 frames for analysis. After discarding frames 1-30, frames 31-60 were used to determine $\delta$. Finally, the Cohesive Energy Density function of Forcite was employed to calculate the $\delta$ value for each frame. This method was repeated for four different TFA densities ranging from $1.43 \mathrm{~mL}$ to $1.58 \mathrm{~g} / \mathrm{mL}$.

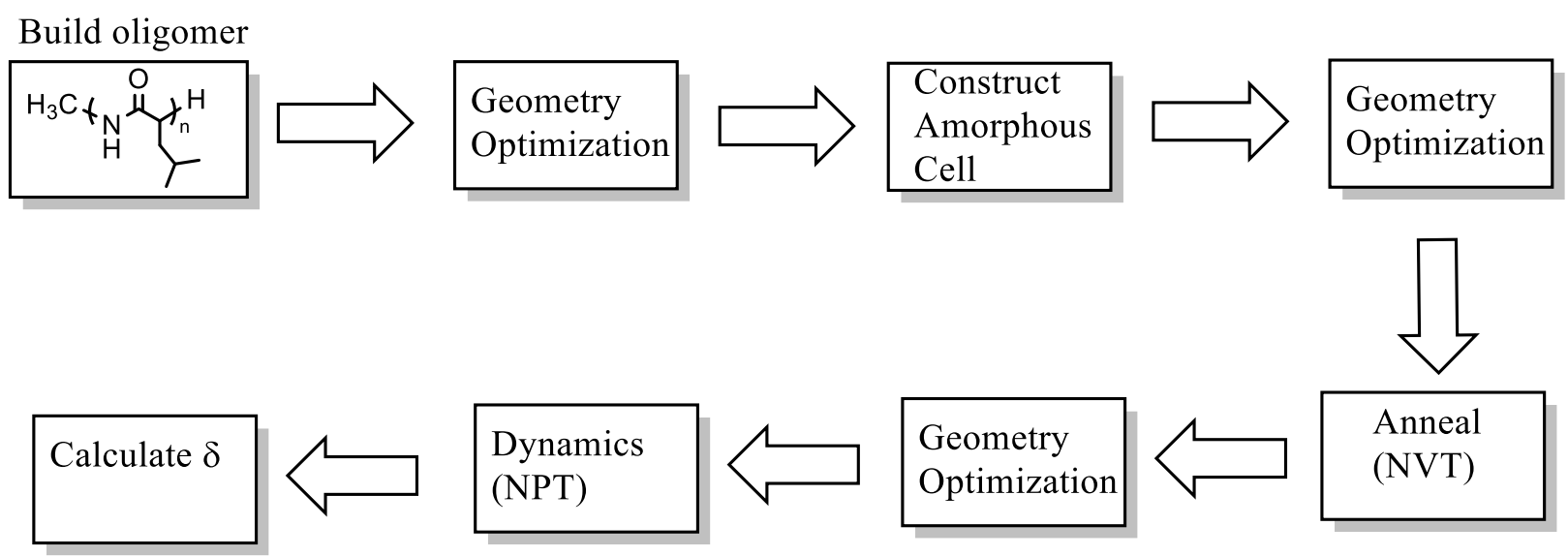

Scheme S4. Flow chart showing method for determining $\delta$ values for oligomers using Materials Studio 2018.

\section{$\underline{\text { DPD Computational Models }}$}

For building and analysis of the molecular models, the Scienomics MAPS 4.2 (Materials and Processes Simulations) software was used, and dissipative particle dynamics (DPD) simulations were performed using the Large-scale Atomic/Molecular Massively Parallel Simulator (LAMMPS) software. Some analysis was also done with Visual Molecular Dynamics (VMD) software version 1.9.1.

First, a custom parameter library for the DPD simulations was created to represent the bonded and nonbonded interaction terms between the beads that represent each of the necessary components in the systems: leucine (L), valine (V), water (W), and TFA. The non-bonded term that represents bead incompatibility is $\boldsymbol{\alpha}$, where a larger value indicates a higher degree of incompatibility. The parameter library also contained terms that represent the dynamics of the 
covalent bond of length $r$ between connected beads as a harmonic spring which has the functional form $\mathrm{k}\left(\mathrm{r}-\mathrm{r}_{0}\right)^{2}$, where $\mathrm{k}$ is the stiffness of the spring/bond and $\mathrm{r}_{0}$ is the equilibrium bond length. The dynamics of the angles $(\theta)$ between three bonded beads were also defined as harmonic with the formula $K\left(\theta-\theta_{0}\right)^{2}$, where $K$ represents the angle stiffness, and $\theta_{0}$ is the equilibrium angle. All of these parameter values are given in Table $\mathrm{S} 2$.

Each of the nine systems were created with the DPD builder in MAPS. First, the PLV 6 oligomer was created, with $5 \mathrm{~L}$ units and $1 \mathrm{~V}$ unit connected by harmonic springs to mimic a chemical bond. To mimic the rigid character of the $\mathrm{PLV}_{6}$ helix, the stiffness of the bond and angle harmonic springs $\left(\mathbf{k}_{\mathrm{ij}}, \mathbf{K}_{\mathbf{i j k}}\right)$ were set to high values. The position of the valine was varied to either the first, second, or third position and the oligomer was treated as a rotationally invariant rod. All simulations were performed in a cubic box with the unit less dimensions of $20 \times 20 \times 20$. Solvent was then added to the simulation box model, and three different solvent conditions were investigated: $100 \mathrm{v} / \mathrm{v} \%$ water, $100 \mathrm{v} / \mathrm{v} \%$ TFA, and $50 \mathrm{v} / \mathrm{v} \%$ TFA. The three different $\mathrm{PLV}_{6}$ oligomers were built with each of three solvent compositions for a total of nine simulation model systems. The simulation boxes were built with $1 \mathrm{wt} . \% \mathrm{PLV}_{6}$ oligomers.

To minimize the initial energy, a geometry optimization calculation was performed on each built system using the conjugated gradient method for 10,000 steps using LAMMPS. Then, DPD simulations were performed under NVT conditions at room temperature utilizing periodic boundary conditions (PBC). Each DPD simulation was conducted for 300,000 steps with a 0.005 timestep.

The output of each simulation was loaded back into MAPS for an analysis of the resulting structures where visual observations were made. Other quantities were calculated in the Visual Molecular Dynamics (VMD) software. The radial distribution function (RDF) was calculated using VMD with a focus on the following groups of atoms in each system: L-L, V-V, L-V, and PLV-PLV. Using the VMD's Analysis feature, the RDF for each group of atoms was calculated over the last 10 frames of the LAMMPS trajectory (out of 101 frames), representing the 300,000 steps of the DPD simulation. 

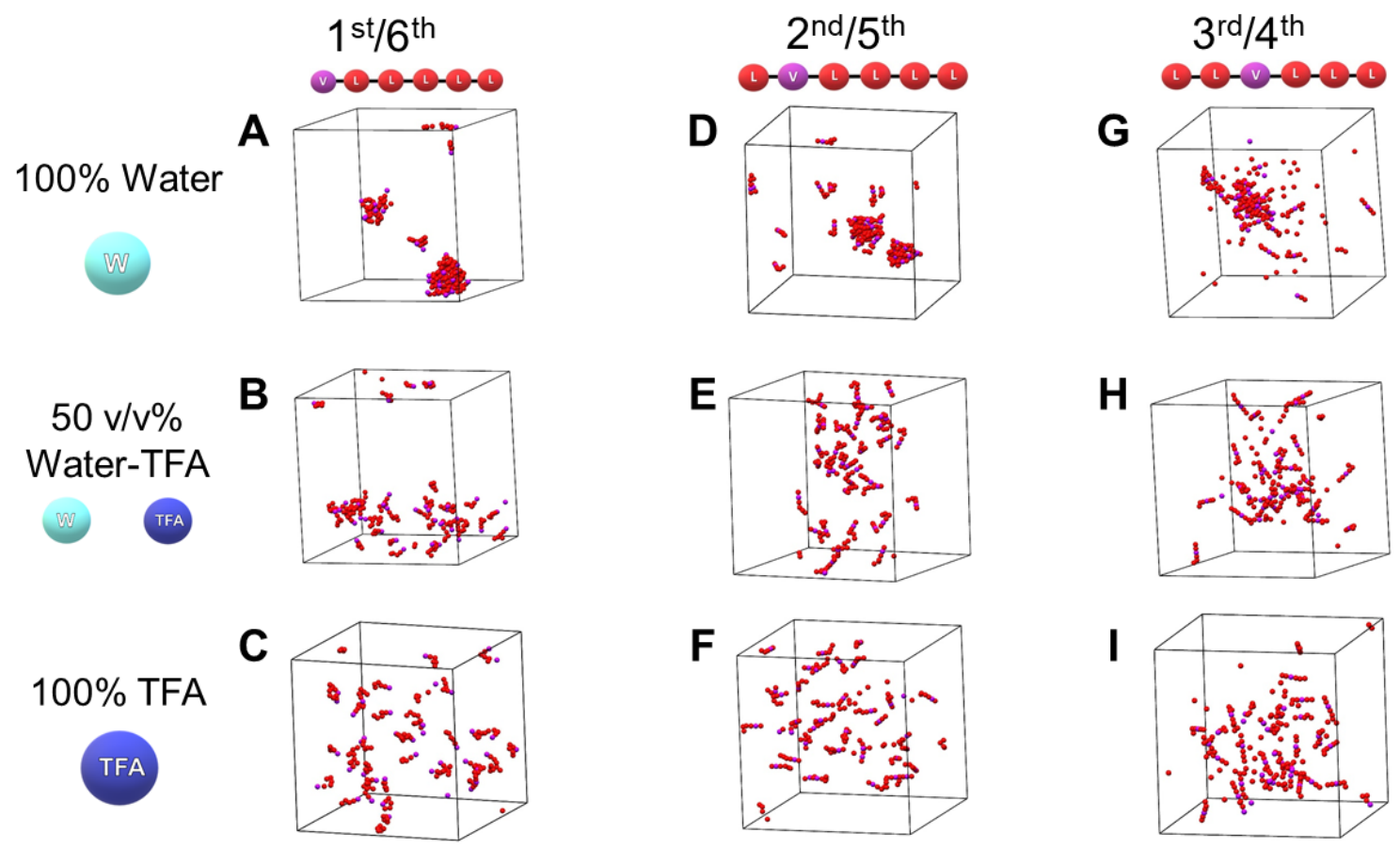

Figure S11. Computational models of an oligomeric PLV block in 100\% water (A, D, G), 50 v/v\% water-TFA (B, E, H), and 100\% TFA (C, F, I). 
Table S2. Parameter Library for the Systems of Interest.

\begin{tabular}{|c|c|c|c|}
\hline \multirow{7}{*}{$\begin{array}{c}\text { Bead } \\
\text { Incompatibility }\end{array}$} & $\mathbf{i}$ & $\mathbf{j}$ & $\boldsymbol{\alpha}_{\mathrm{ij}}$ \\
\hline & $\mathrm{L}$ & V & 26.8 \\
\hline & $\mathrm{L}$ & TFA & 28.2 \\
\hline & $\mathrm{L}$ & W & 47.8 \\
\hline & V & TFA & 27.6 \\
\hline & V & W & 46.8 \\
\hline & W & TFA & 41.9 \\
\hline \multirow{4}{*}{ Harmonic Bonds } & $\mathbf{i}-\mathbf{j}$ & $\mathbf{k}_{\mathrm{ij}}$ & $\mathbf{r}_{0, \mathbf{i j}}$ \\
\hline & L-L & & \\
\hline & $\mathrm{V}-\mathrm{V}$ & 200.0 & 0.5 \\
\hline & L-V & & \\
\hline \multirow{7}{*}{ Harmonic Angles } & $\mathrm{i}-\mathrm{j}-\mathrm{k}$ & $\mathbf{K}_{\mathrm{ijk}}$ & $\theta_{0, \mathrm{ijk}}$ \\
\hline & L-L-L & \multirow{6}{*}{1000.0} & \multirow{6}{*}{180.0} \\
\hline & $\mathrm{V}-\mathrm{V}-\mathrm{V}$ & & \\
\hline & L-L-V & & \\
\hline & L-V-V & & \\
\hline & L-V-L & & \\
\hline & V-L-V & & \\
\hline
\end{tabular}




\section{$\underline{\text { THF Co-Solvent }}$}
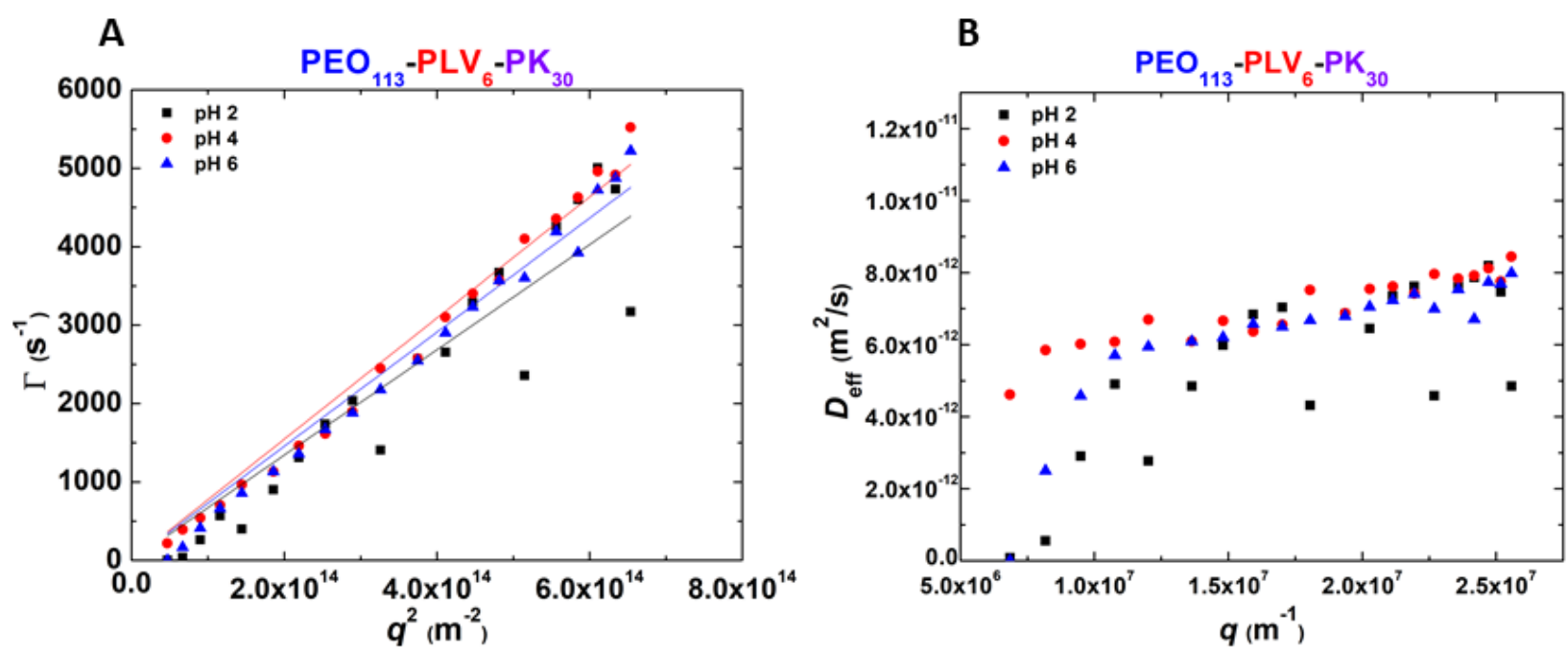

Figure S12. Plots of (A) $\Gamma$ vs. $q^{2}$ and (B) $D_{\text {eff }}$ vs. $q$ for $\mathrm{PEO}_{113}-\mathrm{PLV}_{6}-\mathrm{PK}_{30}$ at $0.05 \mathrm{wt} \%$ in $\mathrm{pH} 2,4$, 6 buffers prepared with a THF co-solvent.

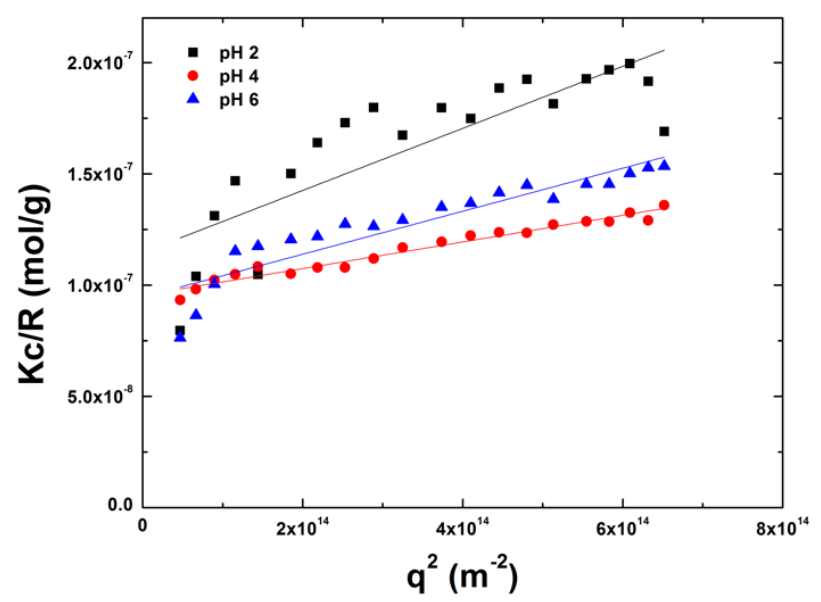

Figure S13. Plot of total scattered intensity vs. $q^{2}$ for $\mathrm{PEO}_{113}-\mathrm{PLV}_{6}-\mathrm{PK}_{30}$ at $0.05 \mathrm{wt} \%$ in $\mathrm{pH} 2,4$, 6 buffers prepared with a THF co-solvent. 


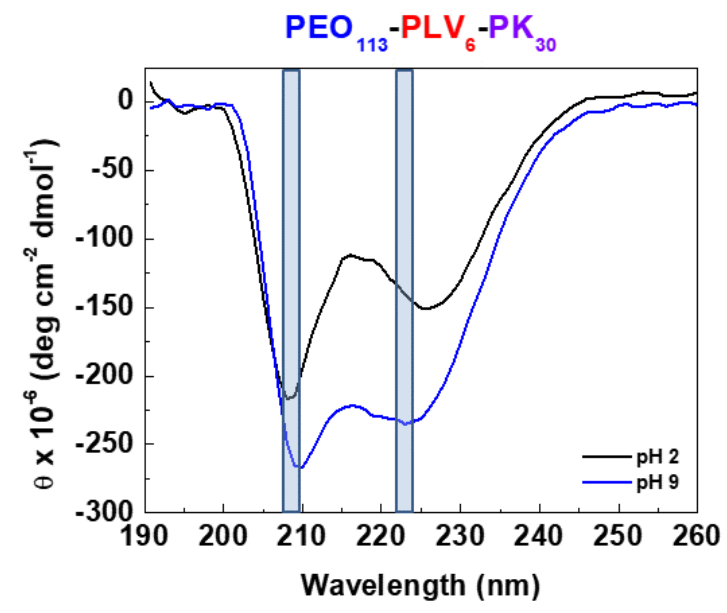

Figure S14. CD Spectra of $\mathrm{PEO}_{113}-\mathrm{PLV}_{6}-\mathrm{PK}_{30}$ at $0.05 \mathrm{wt} \%$ in $\mathrm{pH} 2,9$ buffers prepared from THF co-solvents.

\section{THF Solvent Switch}

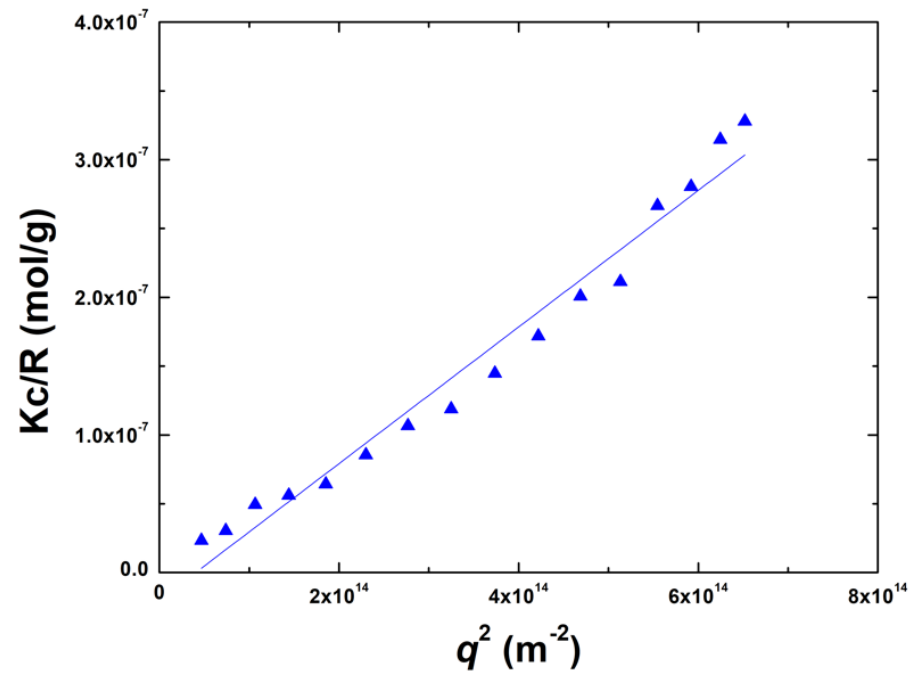

Figure S15. Plot of total scattered intensity vs. $q^{2}$ for $\mathrm{PEO}_{113}-\mathrm{PLV}_{6}-\mathrm{PK}_{30}$ at $0.05 \mathrm{wt} \%$ in $\mathrm{pH} 2$ buffer prepared with a THF solvent switch. 


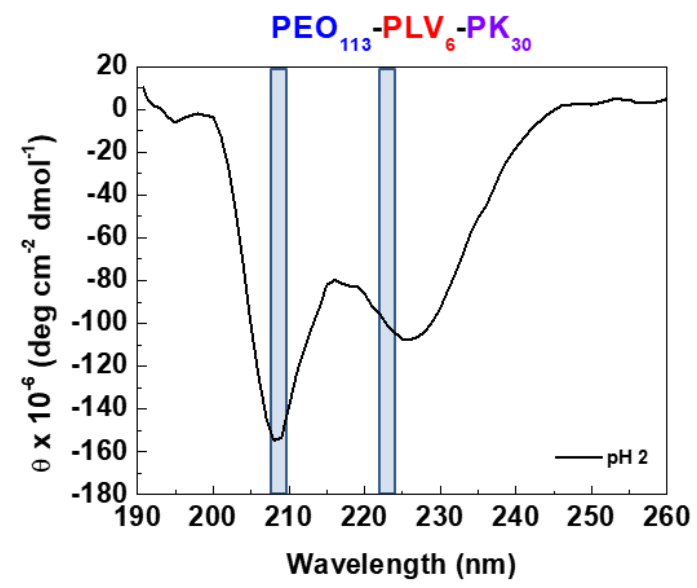

Figure S16. CD Spectra of $\mathrm{PEO}_{113}-\mathrm{PLV}_{6}-\mathrm{PK}_{30}$ at $0.05 \mathrm{wt} \%$ in $\mathrm{pH} 2$ buffer prepared from a THF solvent switch.

\section{TFA Co-Solvent}
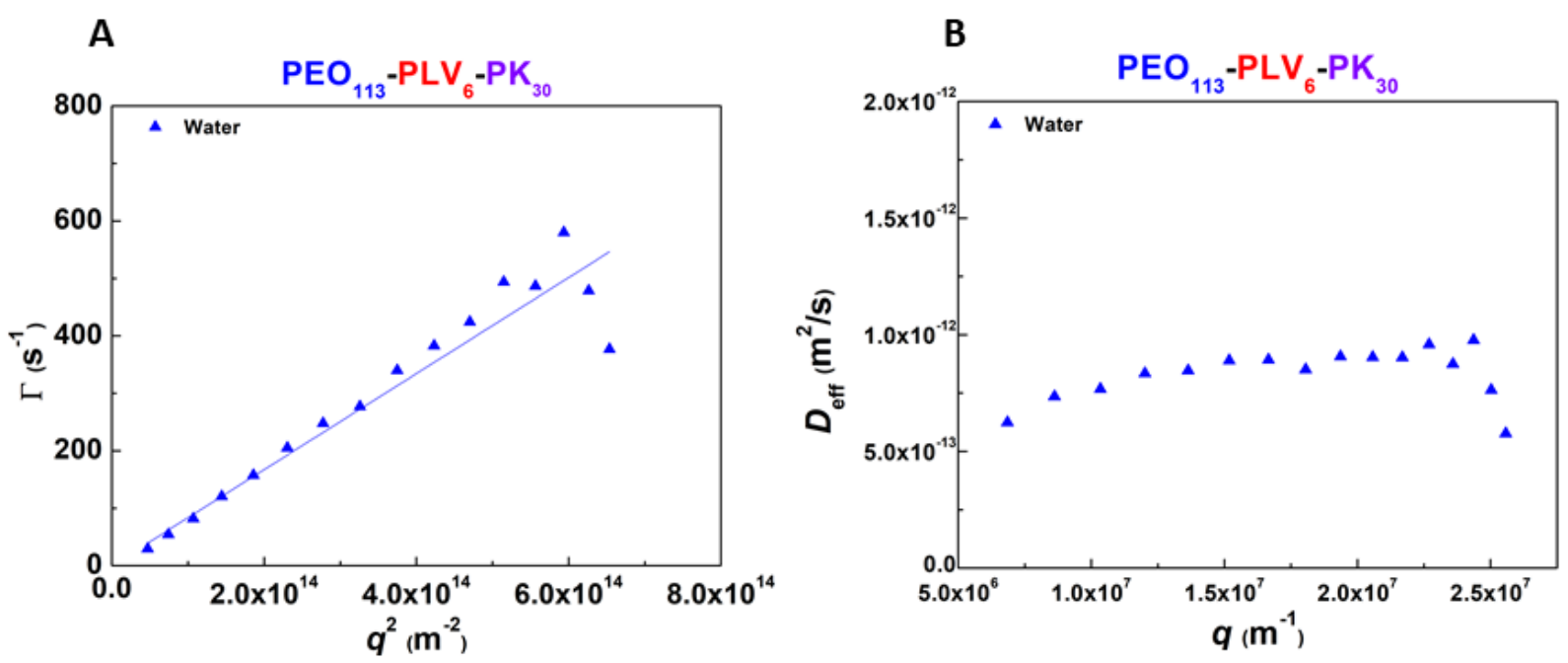

Figure S17. Plots of (A) $\Gamma$ vs. $q^{2}$ and (B) $D_{\text {eff }}$ vs. $q$ for $\mathrm{PEO}_{113}-\mathrm{PLV}_{6}-\mathrm{PK}_{30}$ in $\mathrm{pH} 2$ buffer prepared with a TFA co-solvent. 


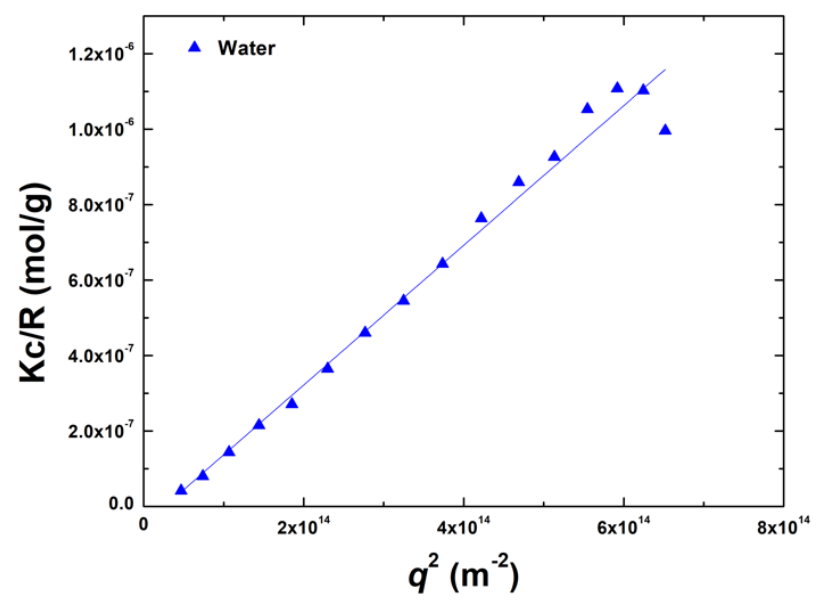

Figure S18. Plot of total scattered intensity vs. $q^{2}$ for $\mathrm{PEO}_{113}-\mathrm{PLV}_{6}-\mathrm{PK}_{30}$ in $\mathrm{pH} 2$ buffer prepared with a TFA co-solvent.

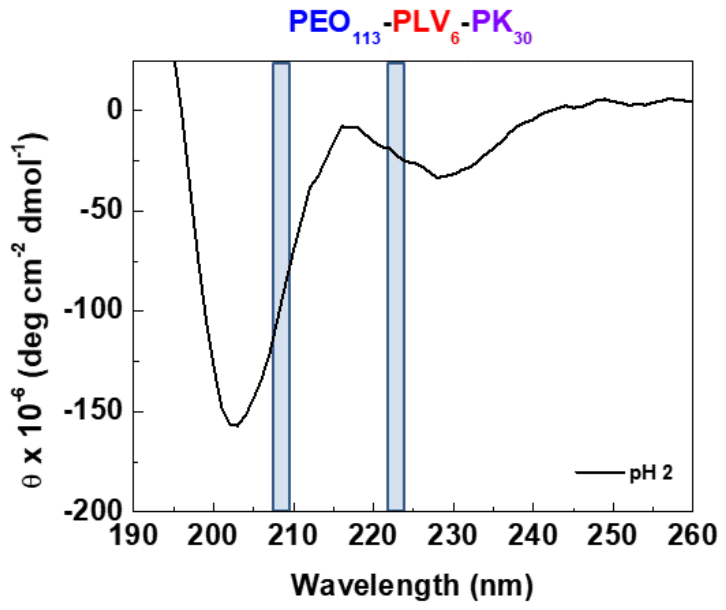

Figure S19. CD Spectra of $\mathrm{PEO}_{113}-\mathrm{PLV}_{6}-\mathrm{PK}_{30}$ at $0.05 \mathrm{wt} \%$ in $\mathrm{pH} 2$ buffer prepared from a TFA co-solvent. 


\section{TFA Solvent Switch}
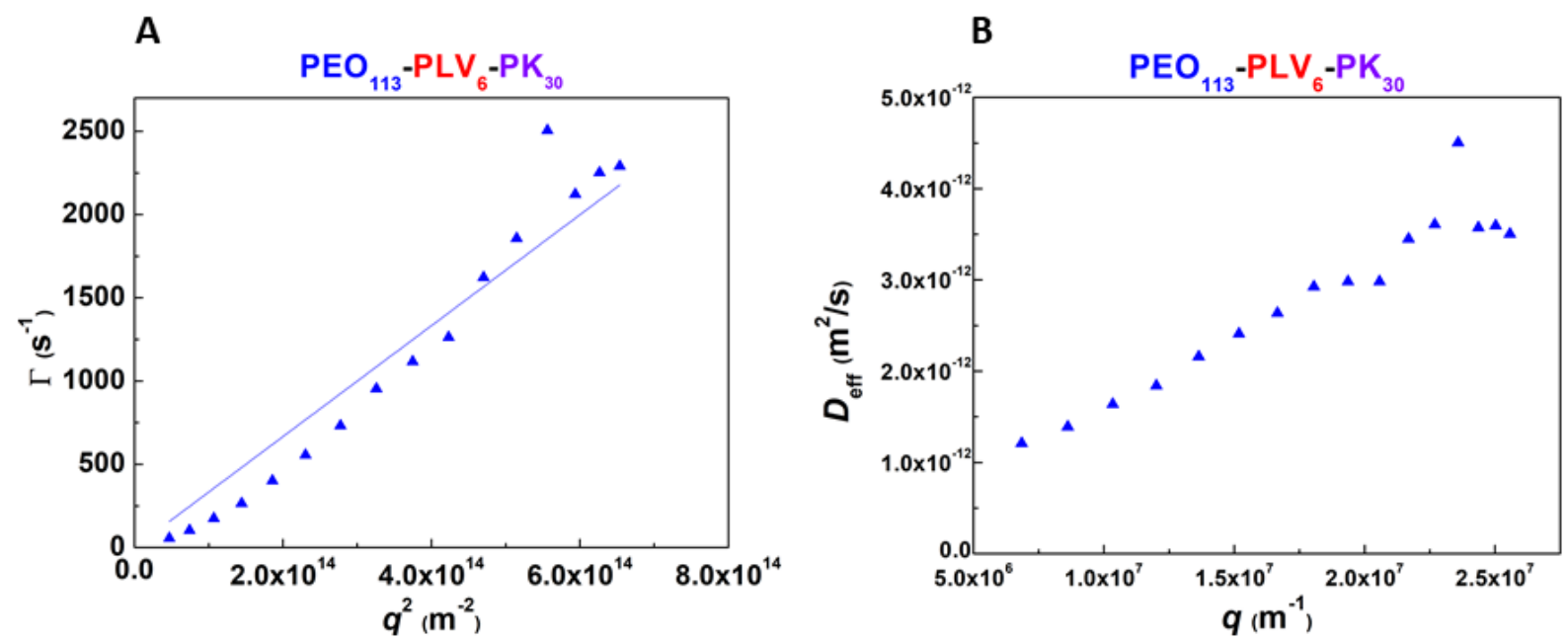

Figure S20. Plots of (A) $\Gamma$ vs. $q^{2}$ and (B) $D_{\text {eff }}$ vs. $q$ for $\mathrm{PEO}_{113}-\mathrm{PLV}_{6}-\mathrm{PK}_{30}$ in $\mathrm{pH} 2$ buffer prepared with a TFA solvent switch.

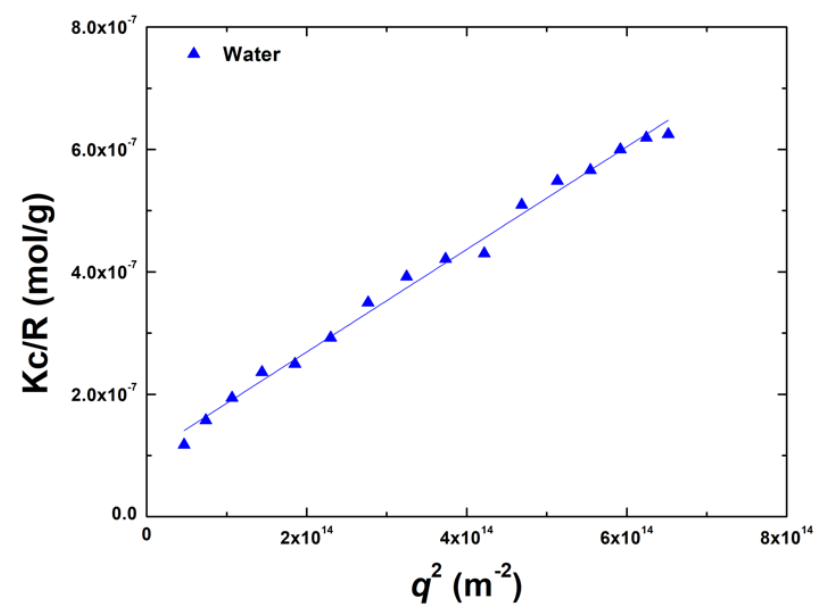

Figure S21. Plot of total scattered intensity vs. $q^{2}$ for $\mathrm{PEO}_{113}-\mathrm{PLV}_{6}-\mathrm{PK}_{30}$ in $\mathrm{pH} 2$ buffer prepared with a TFA solvent switch. 


\section{DMF Co-Solvent}
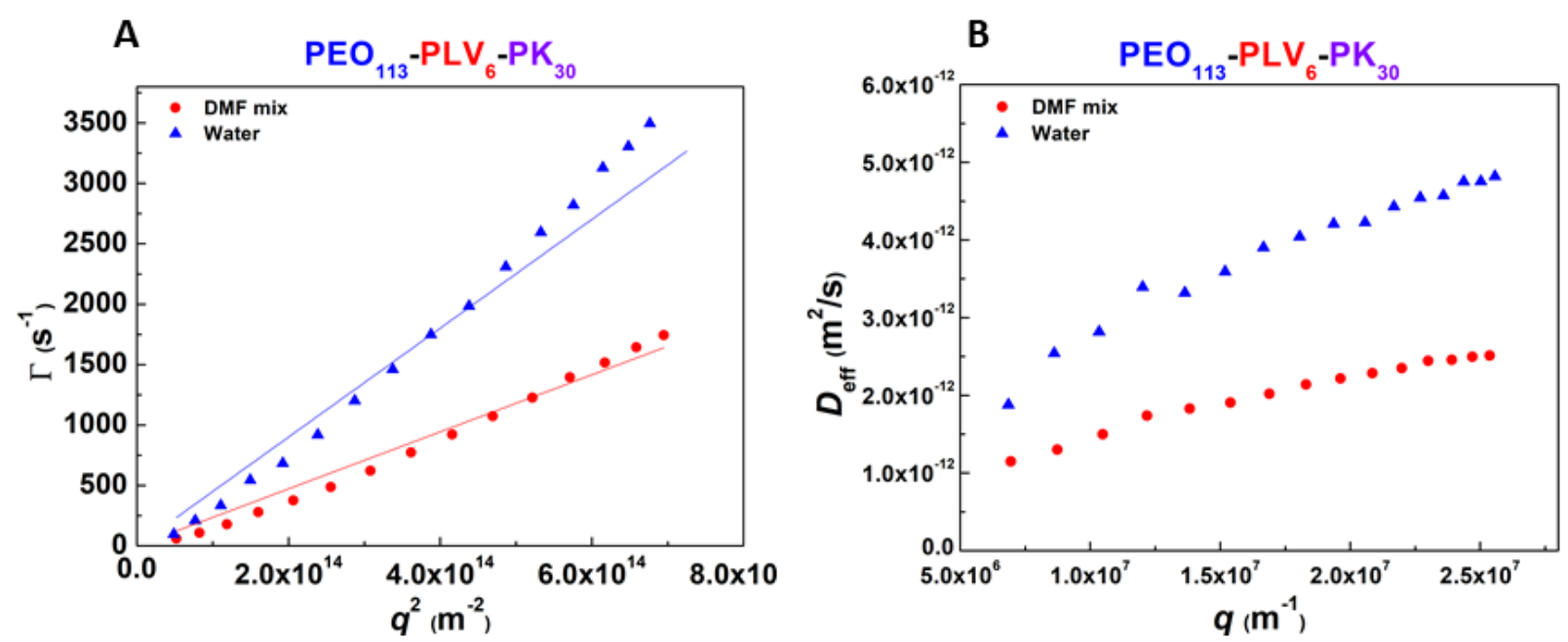

Figure S22. Plots of (A) $\Gamma$ vs. $q^{2}$ and (B) $D_{\text {eff }}$ vs. $q$ for $\mathrm{PEO}_{113}-\mathrm{PLV}_{6}-\mathrm{PK}_{30}$ in $35 \mathrm{wt} \% \mathrm{DMF} / \mathrm{pH} 2$ buffer (red), and $\mathrm{pH} 2$ buffer (blue) prepared with a DMF co-solvent.

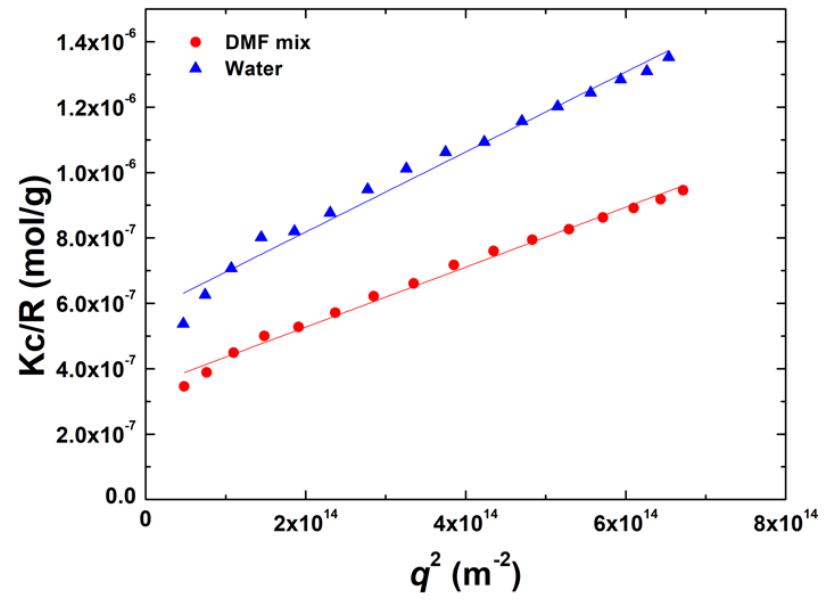

Figure S23. Plot of total scattered intensity vs. $q^{2}$ for $\mathrm{PEO}_{113}-\mathrm{PLV}_{6}-\mathrm{PK}_{30} 35 \mathrm{wt} \% \mathrm{DMF} / \mathrm{pH} 2$ buffer (red), and $\mathrm{pH} 2$ buffer (blue) prepared with a DMF co-solvent. 


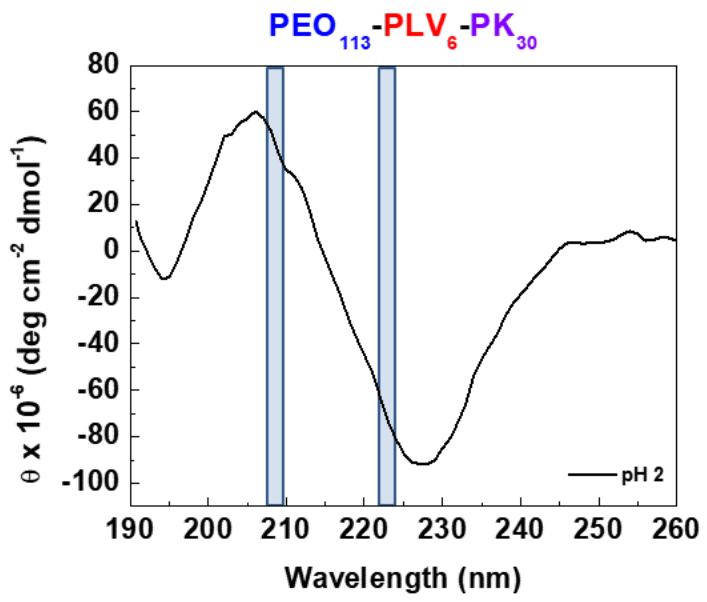

Figure S24. CD Spectra of $\mathrm{PEO}_{113}-\mathrm{PLV}_{6}-\mathrm{PK}_{30}$ at $0.05 \mathrm{wt} \%$ in $\mathrm{pH} 2$ buffer prepared from a DMF co-solvent. Peak at $207 \mathrm{~nm}$ and $225 \mathrm{~nm}$ is due to residual DMF in the solution.

\section{DMF Solvent Switch}
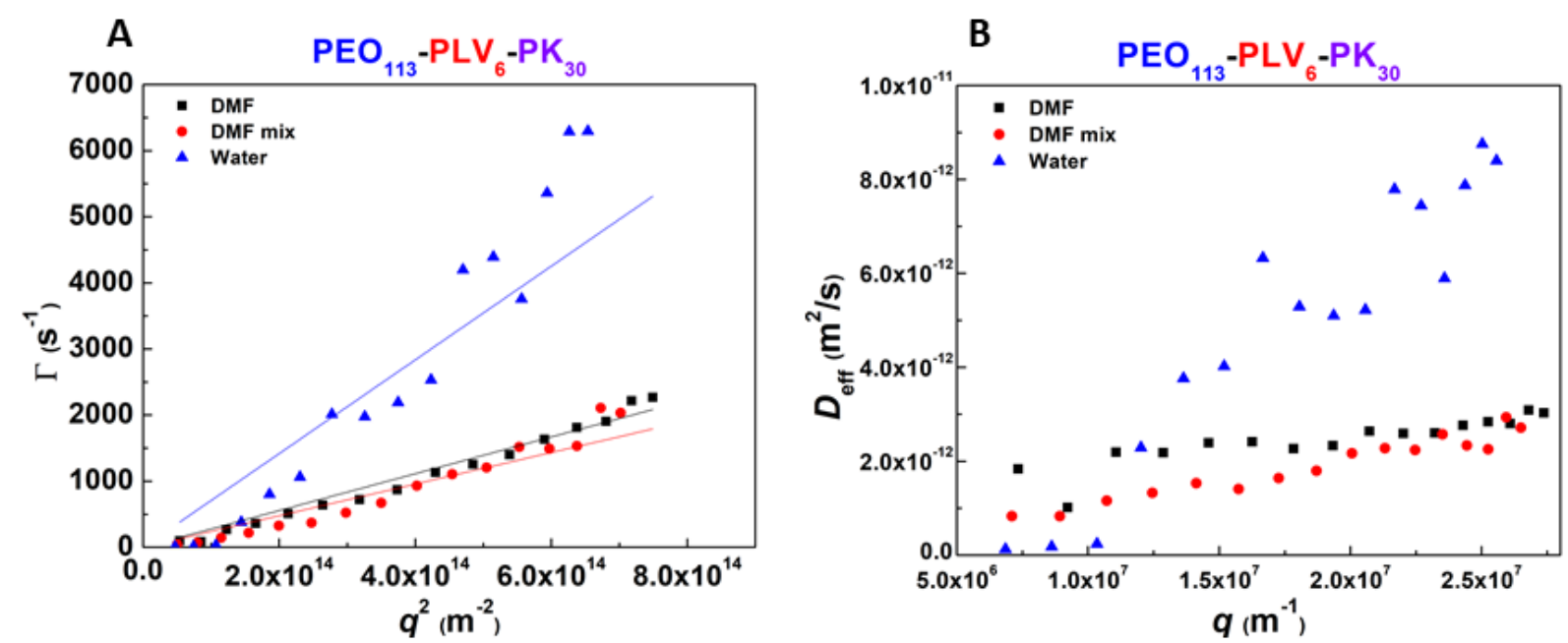

Figure S25. Plots of (A) $\Gamma$ vs. $q^{2}$ and (B) $D_{\text {eff }}$ vs. $q$ for $\mathrm{PEO}_{113}-\mathrm{PLV}_{6}-\mathrm{PK}_{30}$ at $0.06 \mathrm{wt} \%$ in DMF (black), 50/50 v/v\% DMF/pH 2 buffer (red), and pH 2 buffer (blue) prepared with a DMF solvent switch. 


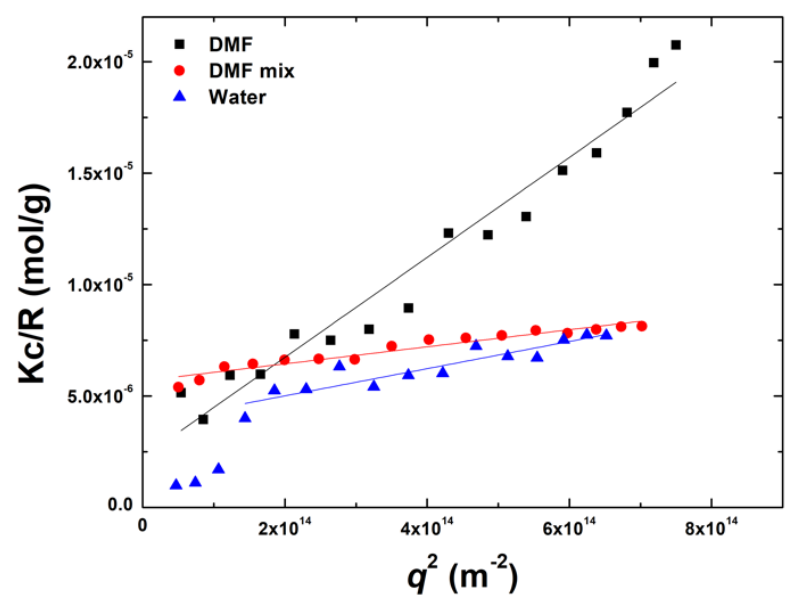

Figure S26. Plot of total scattered intensity vs. $q^{2}$ for $\mathrm{PEO}_{113}-\mathrm{PLV}_{6}-\mathrm{PK}_{30}$ at $0.06 \mathrm{wt} \%$ in DMF (black), 50/50 v/v\% DMF/pH 2 buffer (red), and $\mathrm{pH} 2$ buffer (blue) prepared with a DMF solvent switch.

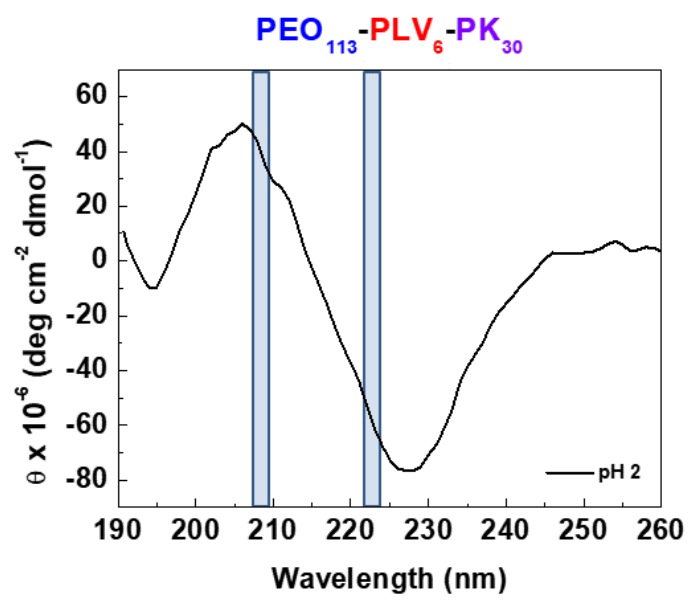

Figure S27. CD Spectra of $\mathrm{PEO}_{113}-\mathrm{PLV}_{6}-\mathrm{PK}_{30}$ at $0.06 \mathrm{wt} \%$ in $\mathrm{pH} 2$ buffer prepared from a DMF solvent switch. Peak at $207 \mathrm{~nm}$ and $225 \mathrm{~nm}$ is due to residual DMF in the solution. 


\section{Dioxane Co-solvent}
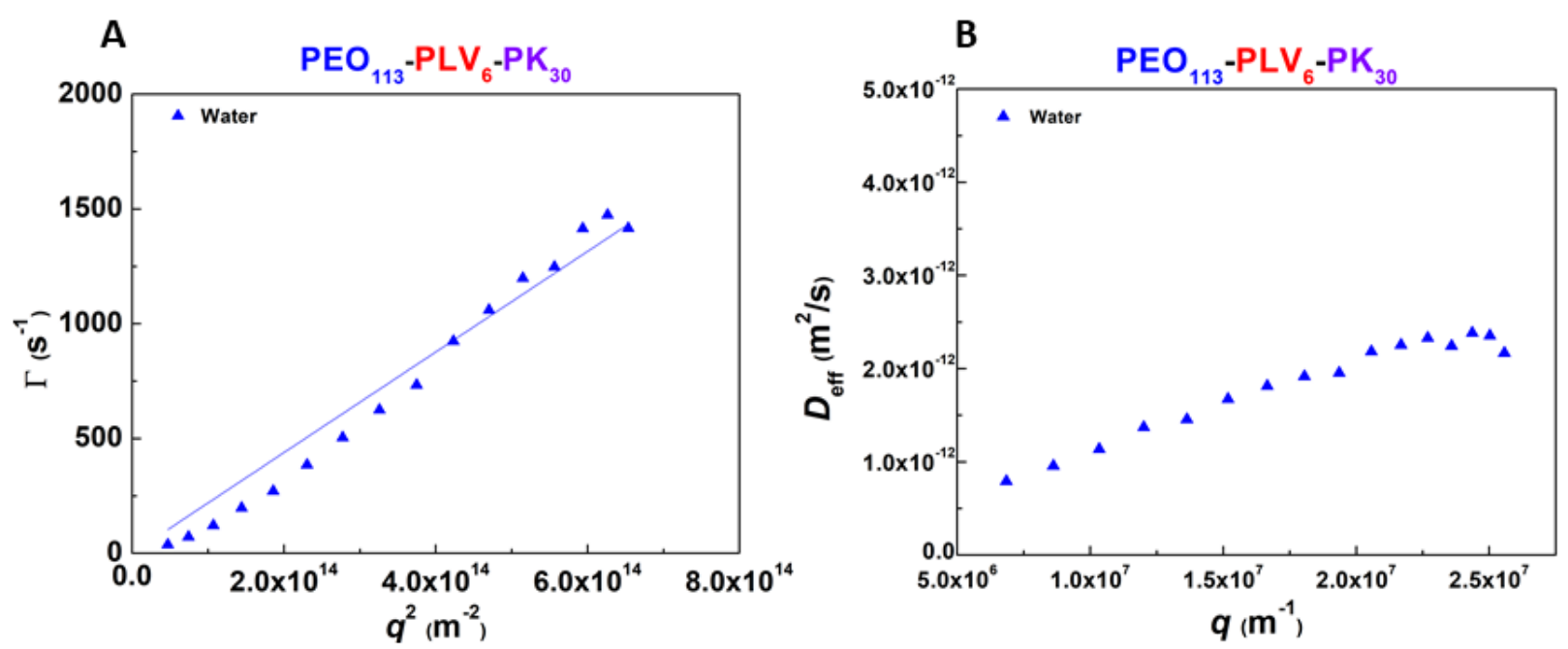

Figure S28. Plots of (A) $\Gamma$ vs. $q^{2}$ and (B) $D_{\text {eff }}$ vs. $q$ for $\mathrm{PEO}_{113}-\mathrm{PLV}_{6}-\mathrm{PK}_{30}$ at $0.05 \mathrm{wt} \%$ in $\mathrm{pH} 2$ buffer, prepared with a dioxane co-solvent.

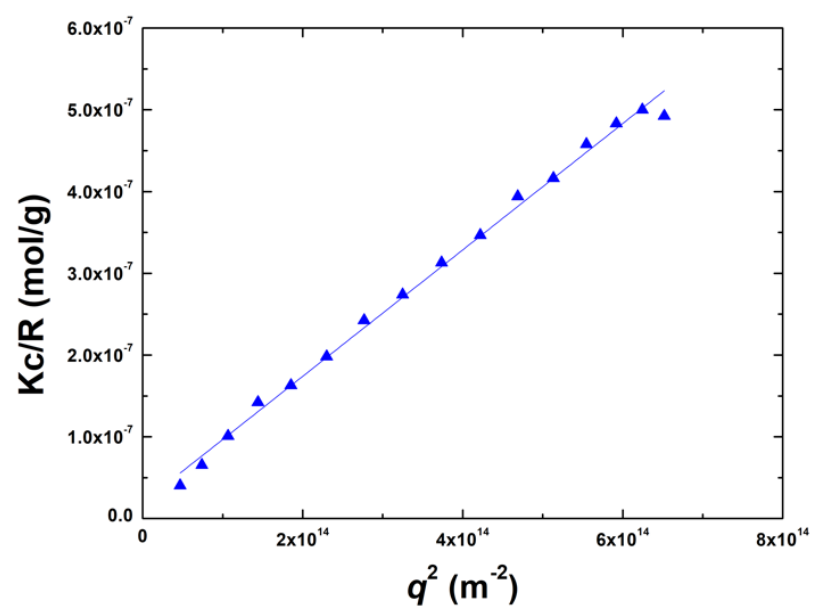

Figure S29. Plot of total scattered intensity vs. $q^{2}$ for $\mathrm{PEO}_{113}-\mathrm{PLV}_{6}-\mathrm{PK}_{30}$ at $0.05 \mathrm{wt} \%$ in $\mathrm{pH} 2$ buffer, prepared with a dioxane co-solvent. 


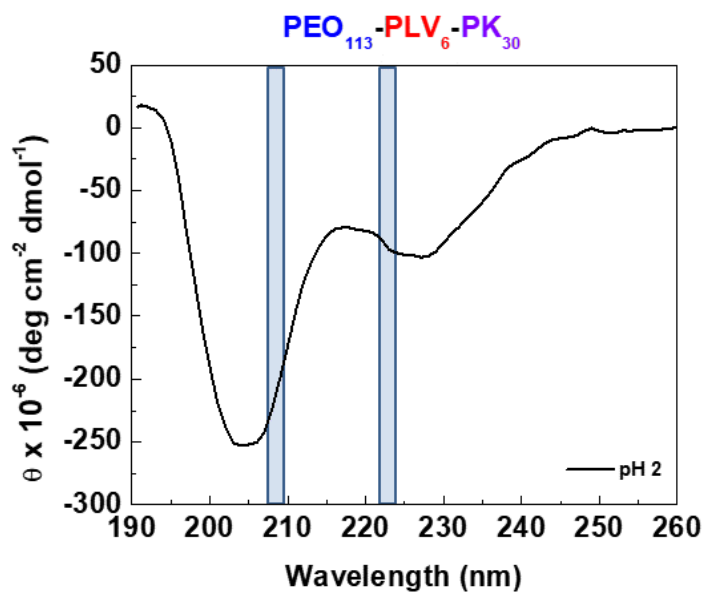

Figure S30. CD Spectra of $\mathrm{PEO}_{113}-\mathrm{PLV}_{6}-\mathrm{PK}_{30}$ at $0.05 \mathrm{wt} \%$ in $\mathrm{pH} 2$ buffer prepared from a dioxane co-solvent.

\section{Dioxane Solvent Switch}
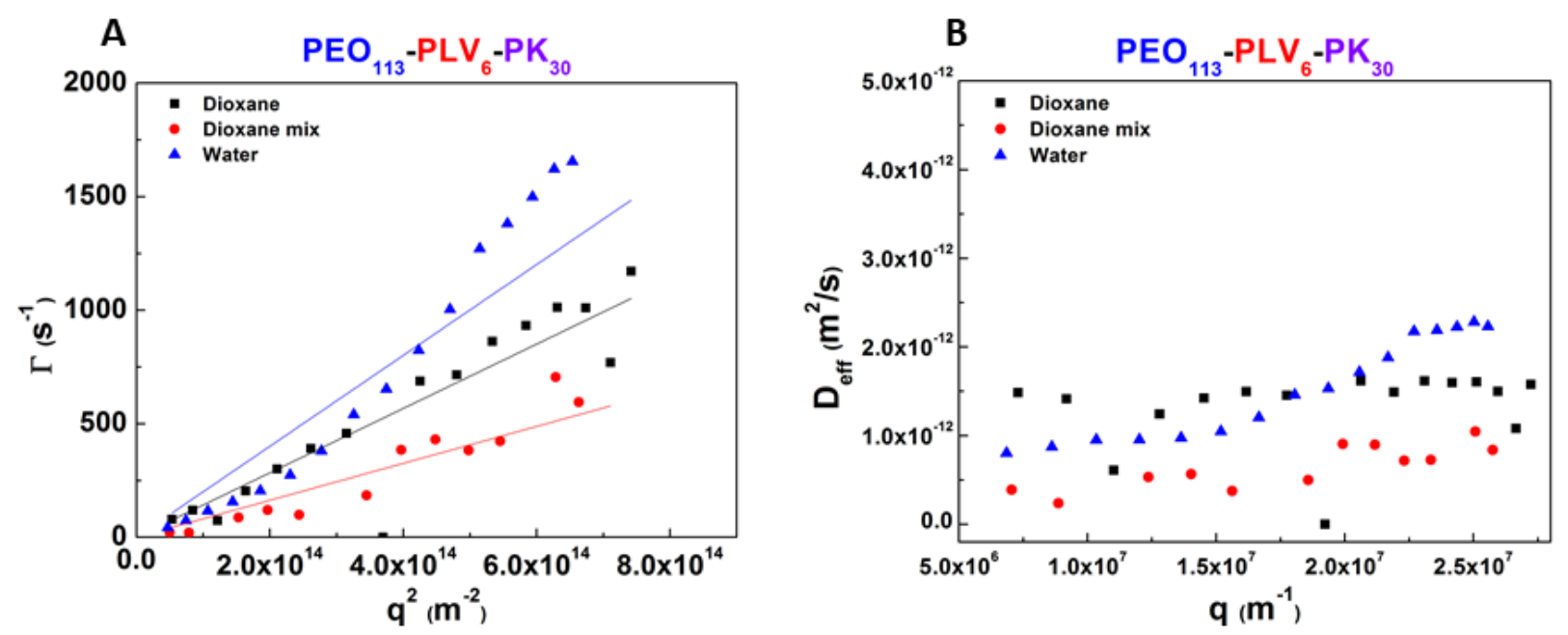

Figure S31. Plots of (A) $\Gamma$ vs. $q^{2}$ and (B) $D_{\text {eff }}$ vs. $q$ for $\mathrm{PEO}_{113}-\mathrm{PLV}_{6}-\mathrm{PK}_{30}$ at $0.05 \mathrm{wt} \%$ in dioxane (black), 50/50 v/v\% dioxane/pH 2 buffer (red), and $\mathrm{pH} 2$ buffer (blue) prepared with a dioxane solvent switch. 


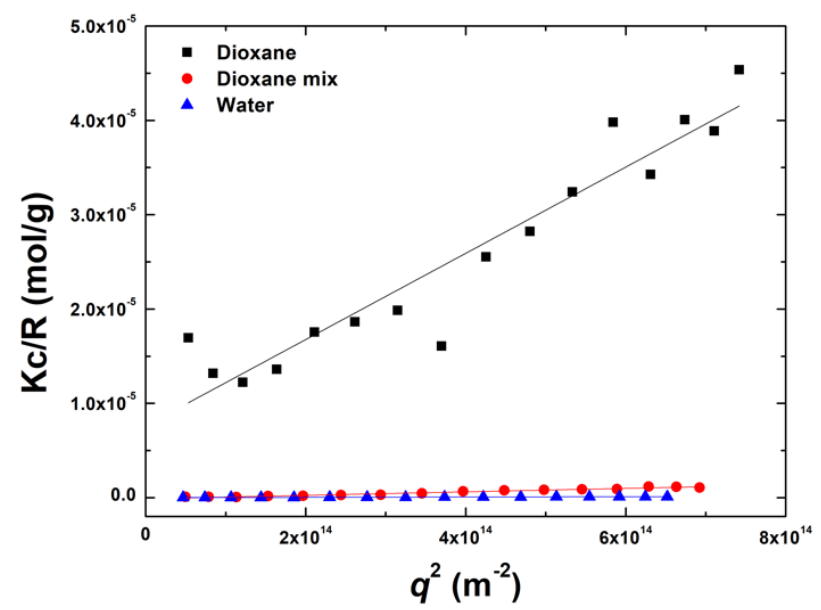

Figure S32. Plot of total scattered intensity vs. $q^{2}$ for $\mathrm{PEO}_{113}-\mathrm{PLV}_{6}-\mathrm{PK}_{30}$ at $0.05 \mathrm{wt} \%$ in dioxane (black), 50/50 v/v\% dioxane/pH 2 buffer (red), and $\mathrm{pH} 2$ buffer (blue) prepared with a dioxane solvent switch.

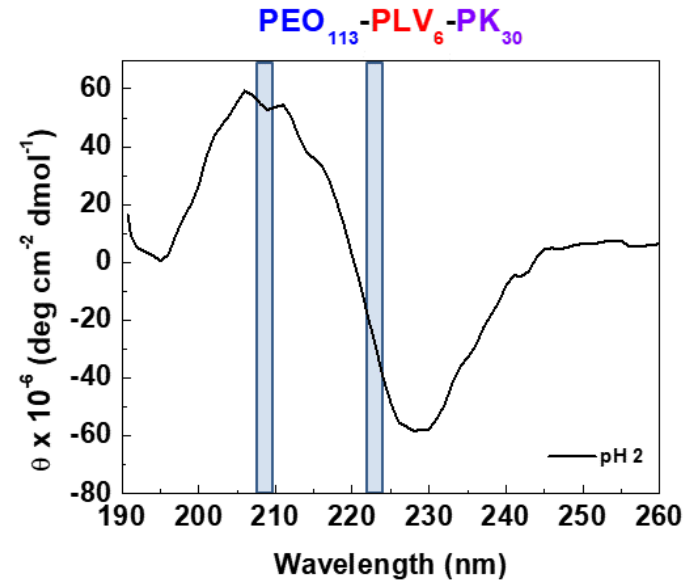

Figure S33. CD Spectra of $\mathrm{PEO}_{113}-\mathrm{PLV}_{6}-\mathrm{PK}_{30}$ at $0.05 \mathrm{wt} \%$ in $\mathrm{pH} 2$ buffer prepared from a dioxane solvent switch. Peak at $208 \mathrm{~nm}$ and $230 \mathrm{~nm}$ is due to residual dioxane in the solution. 


\section{DMSO Co-Solvent}
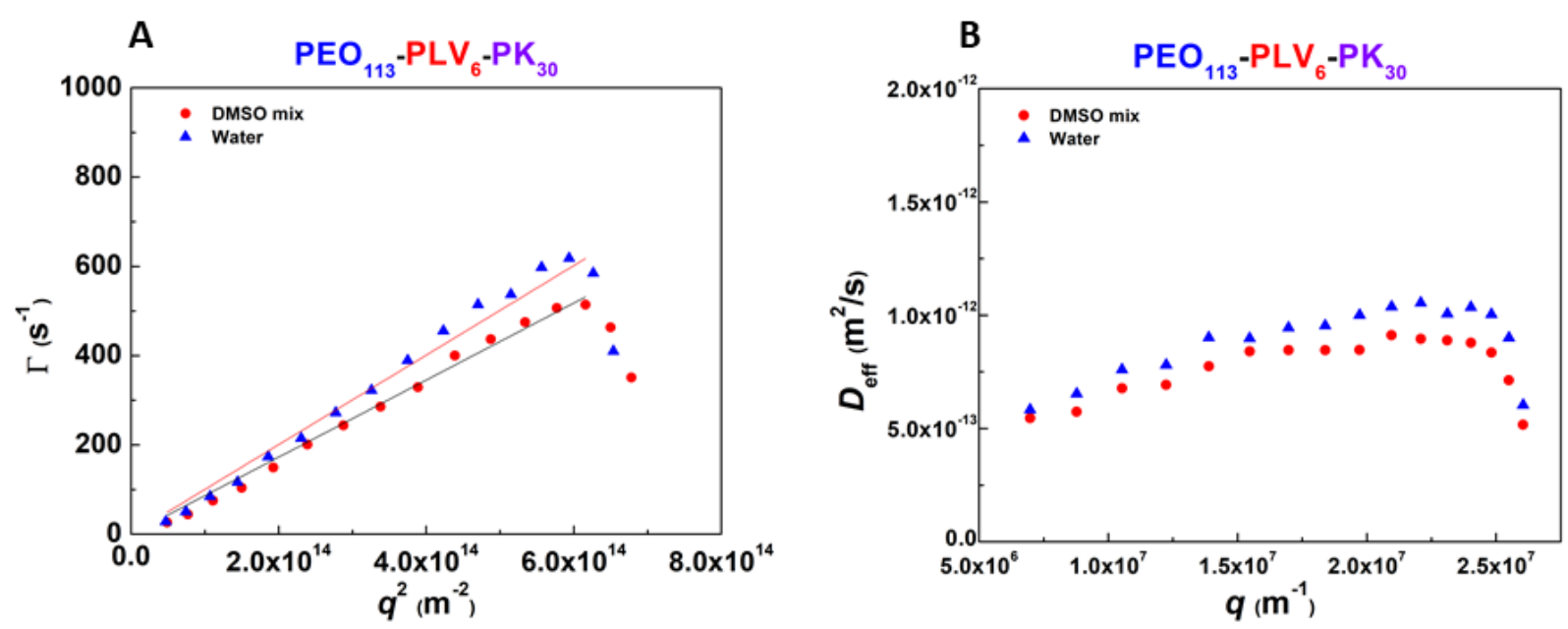

Figure S34. Plots of (A) $\Gamma$ vs. $q^{2}$ and (B) $D_{\text {eff }}$ vs. $q$ for $\mathrm{PEO}_{113}-\mathrm{PLV}_{6}-\mathrm{PK}_{30}$ in $35 \mathrm{wt} \% \mathrm{DMSO} / \mathrm{pH}$ 2 buffer (red), and pH 2 buffer (blue) prepared with a DMSO co-solvent.

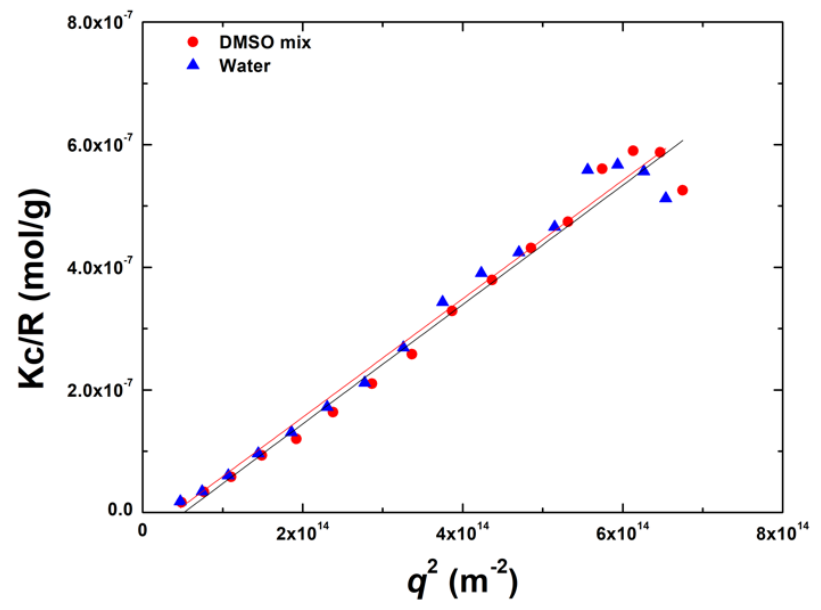

Figure S35. Plot of total scattered intensity vs. $q^{2}$ for $\mathrm{PEO}_{113}-\mathrm{PLV}_{6}-\mathrm{PK}_{30} 35 \mathrm{wt} \% \mathrm{DMSO} / \mathrm{pH} 2$ buffer (red), and pH 2 buffer (blue) prepared with a DMSO co-solvent. 


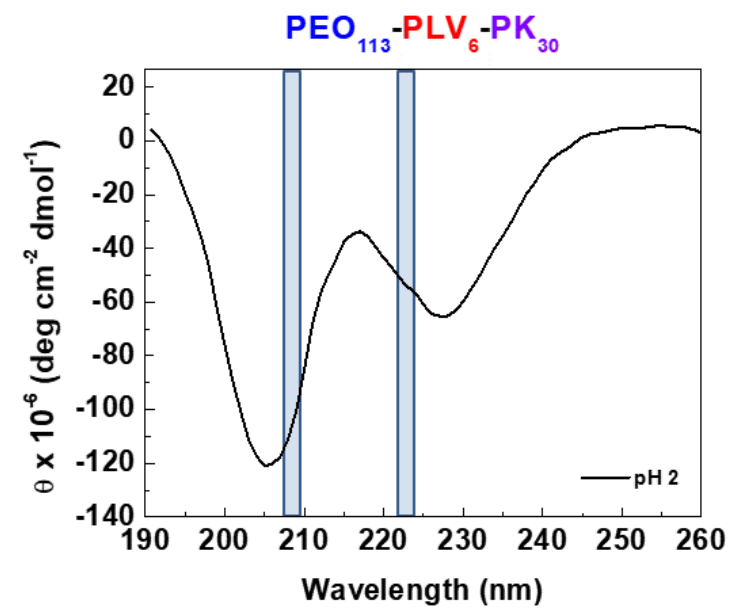

Figure S36. CD Spectra of $\mathrm{PEO}_{113}-\mathrm{PLV}_{6}-\mathrm{PK}_{30}$ at $0.09 \mathrm{wt} \%$ in $\mathrm{pH} 2$ buffer prepared from a DMSO co-solvent.

\section{DMSO Solvent Switch}
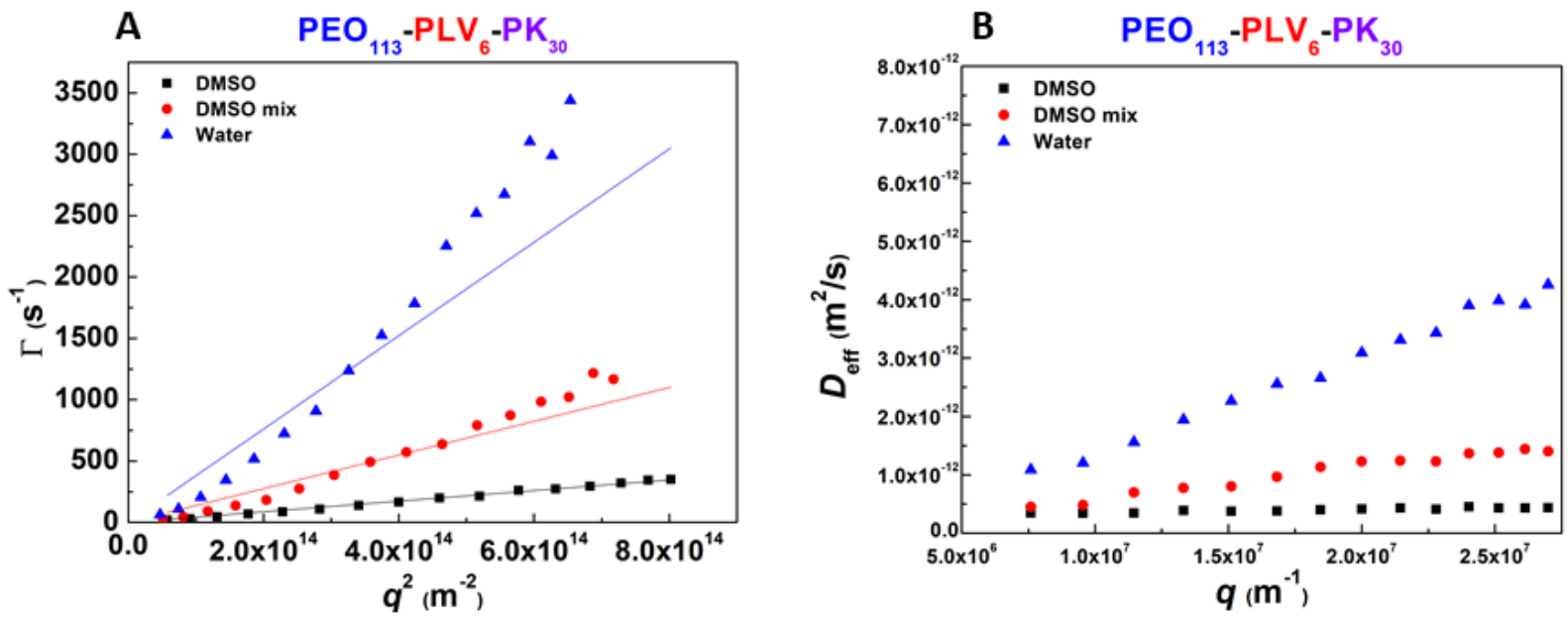

Figure S37. Plots of (A) $\Gamma$ vs. $q^{2}$ and (B) $D_{\text {eff }}$ vs. $q$ for $\mathrm{PEO}_{113}-\mathrm{PLV}_{6}-\mathrm{PK}_{30}$ at $0.05 \mathrm{wt} \%$ in DMSO (black), 50/50 v/v\% DMSO/pH 2 buffer (red), and $\mathrm{pH} 2$ buffer (blue) prepared with a DMSO solvent switch. 


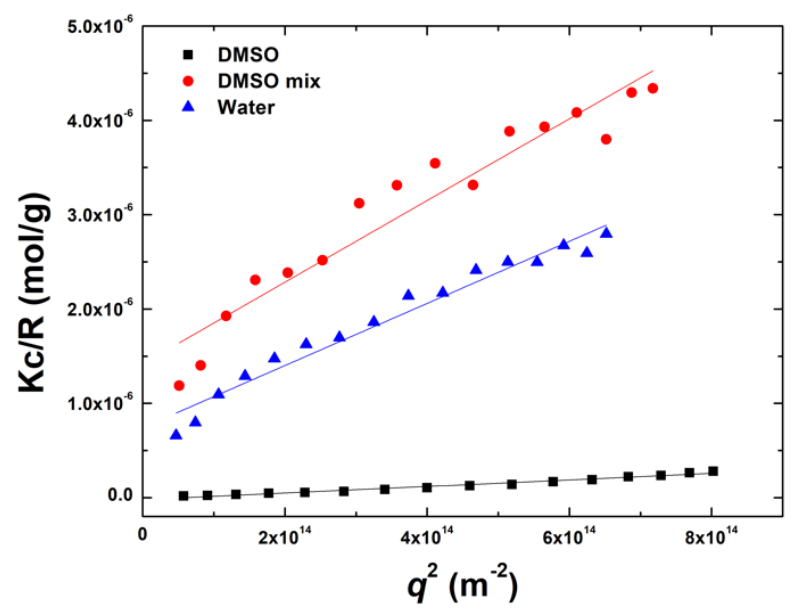

Figure S38. Plot of total scattered intensity vs. $q^{2}$ for $\mathrm{PEO}_{113}-\mathrm{PLV}_{6}-\mathrm{PK}_{30}$ at $0.05 \mathrm{wt} \%$ in dioxane (black), 50/50 v/v\% dioxane/pH 2 buffer (red), and $\mathrm{pH} 2$ buffer (blue) prepared with a dioxane solvent switch.

\section{pH 2 Buffer}
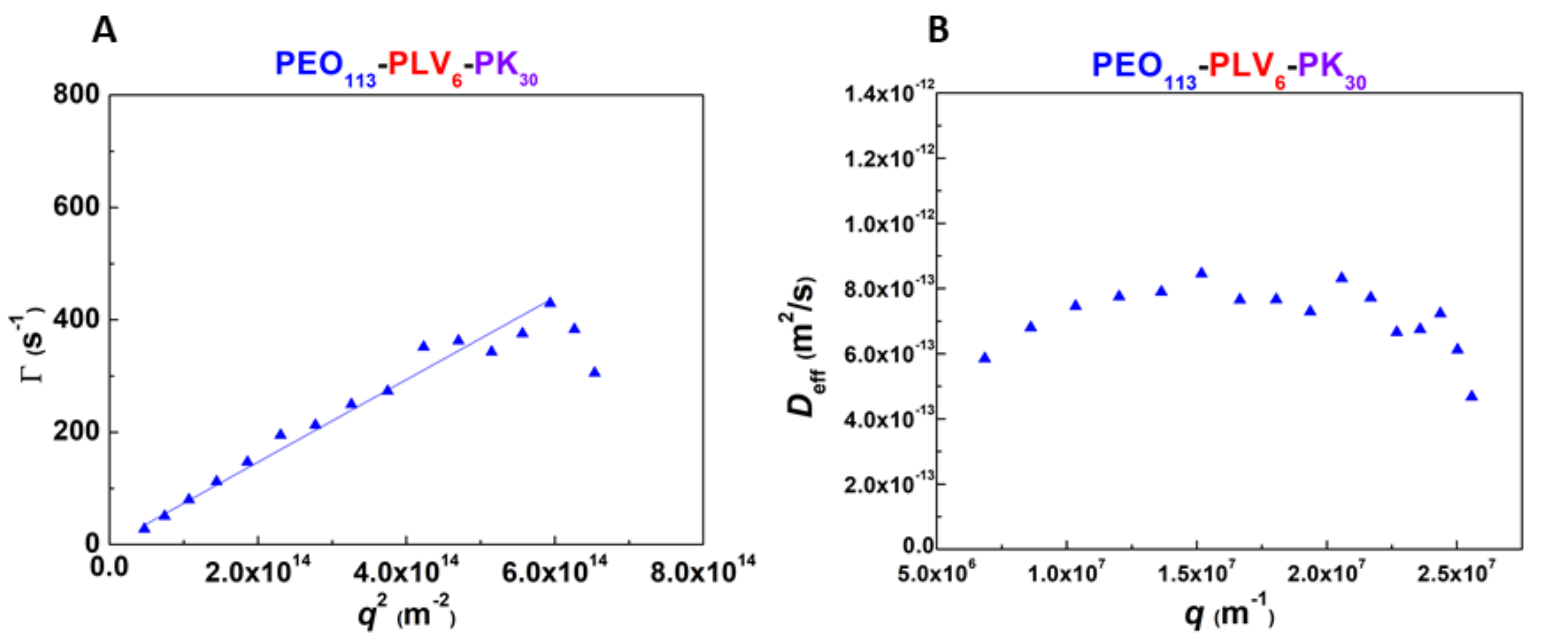

Figure S39. Plots of (A) $\Gamma$ vs. $q^{2}$ and (B) $D_{\text {eff }}$ vs. $q$ for $\mathrm{PEO}_{113}-\mathrm{PLV}_{6}-\mathrm{PK}_{30}$ at $0.05 \mathrm{wt} \%$ in $\mathrm{pH} 2$ buffer. 


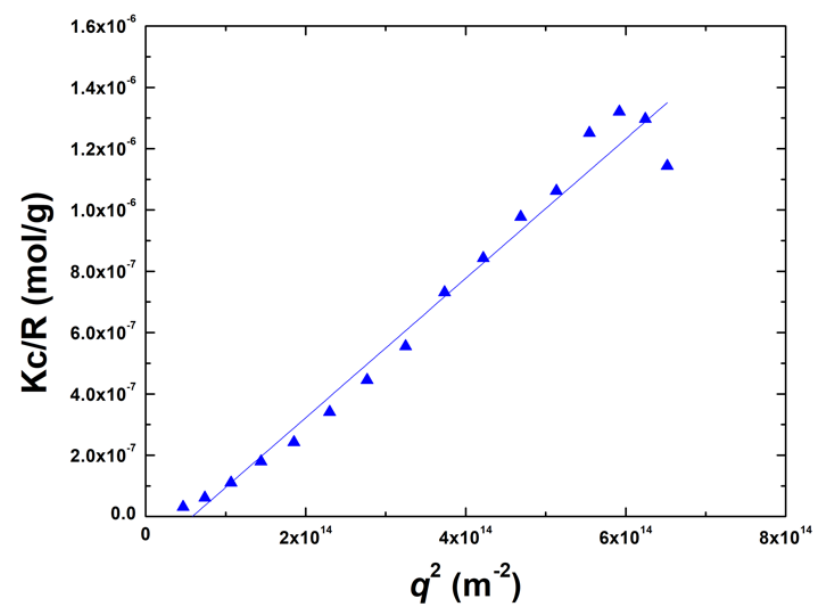

Figure S40. Plot of total scattered intensity vs. $q^{2}$ for $\mathrm{PEO}_{113}-\mathrm{PLV}_{6}-\mathrm{PK}_{30}$ at $0.05 \mathrm{wt} \% \mathrm{pH} 2$ buffer.

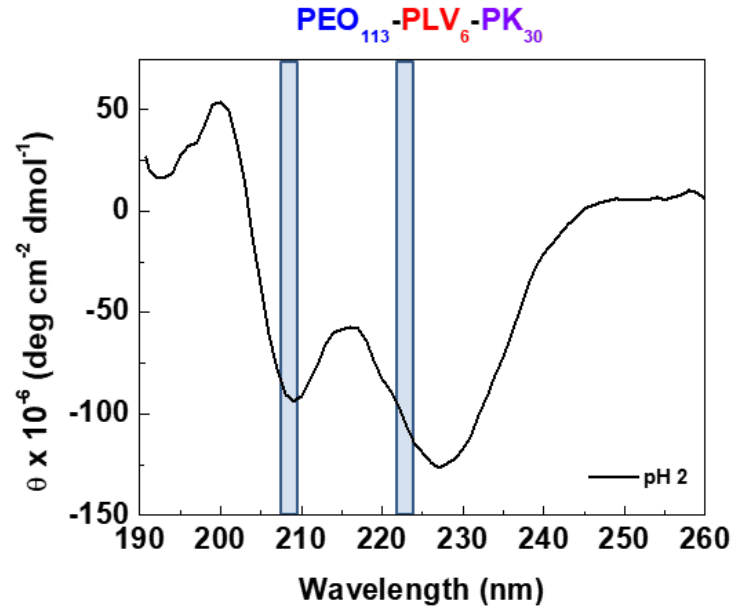

Figure S41. CD Spectra of $\mathrm{PEO}_{113}-\mathrm{PLV}_{6}-\mathrm{PK}_{30}$ at $0.05 \mathrm{wt} \%$ in $\mathrm{pH} 2$ buffer. 


\section{Urea Solvent Switch}
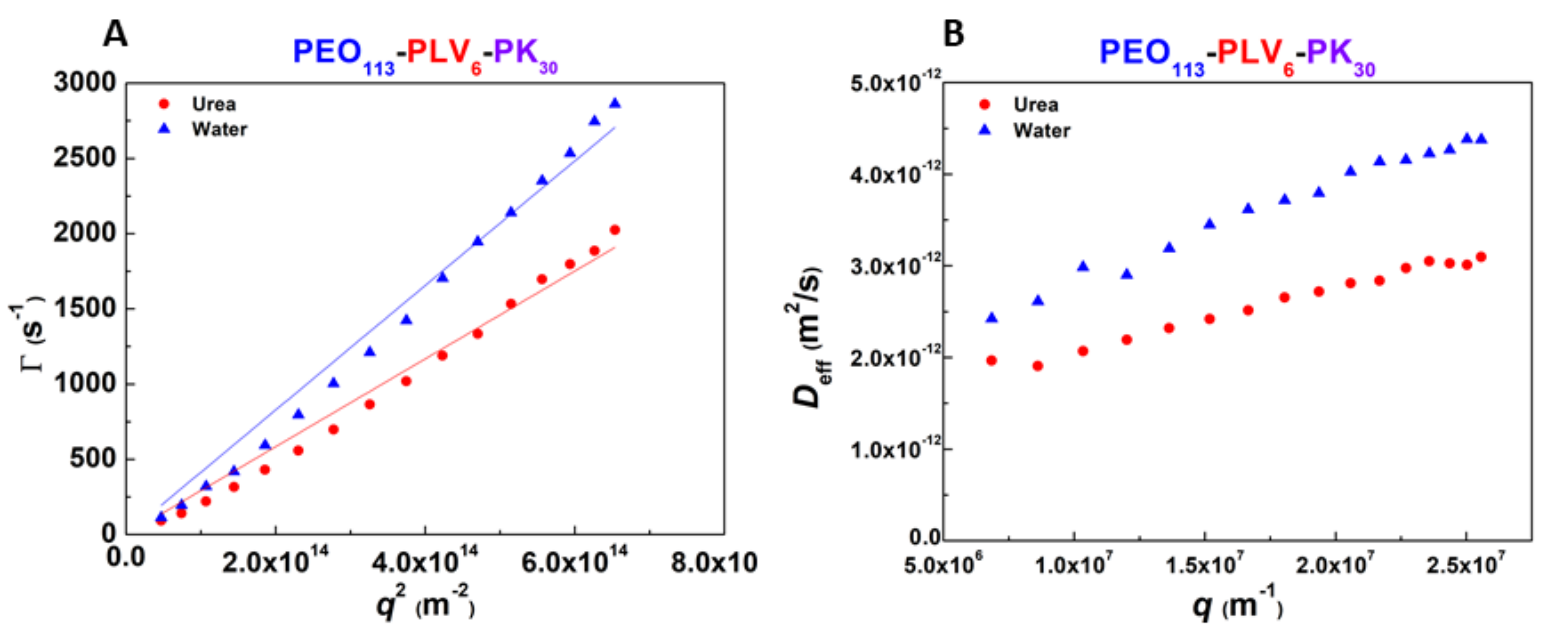

Figure S42. Plots of (A) $\Gamma$ vs. $q^{2}$ and (B) $\mathrm{D}_{\text {eff }}$ vs. $q$ for $\mathrm{PEO}_{113}-\mathrm{PLV}_{6}-\mathrm{PK}_{30}$ at $0.07 \mathrm{wt} \%$ in $5 \mathrm{M}$ Urea solution (red) and pH 2 buffer (blue). The $R_{\mathrm{h}}$ of the final assemblies was $59 \mathrm{~nm}$.

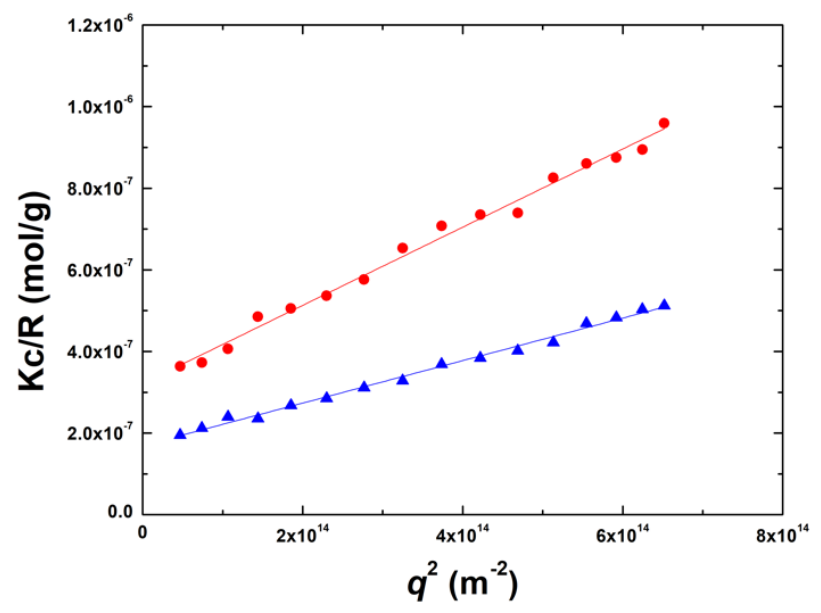

Figure S43. Plot of total scattered intensity vs. $q^{2}$ for $\mathrm{PEO}_{113}-\mathrm{PLV}_{6}-\mathrm{PK}_{30}$ at $0.07 \mathrm{wt} \%$ in $5 \mathrm{M}$ Urea solution (red) and pH 2 buffer (blue). The $R_{\mathrm{g}}$ of the final assemblies was $96 \mathrm{~nm}$. 


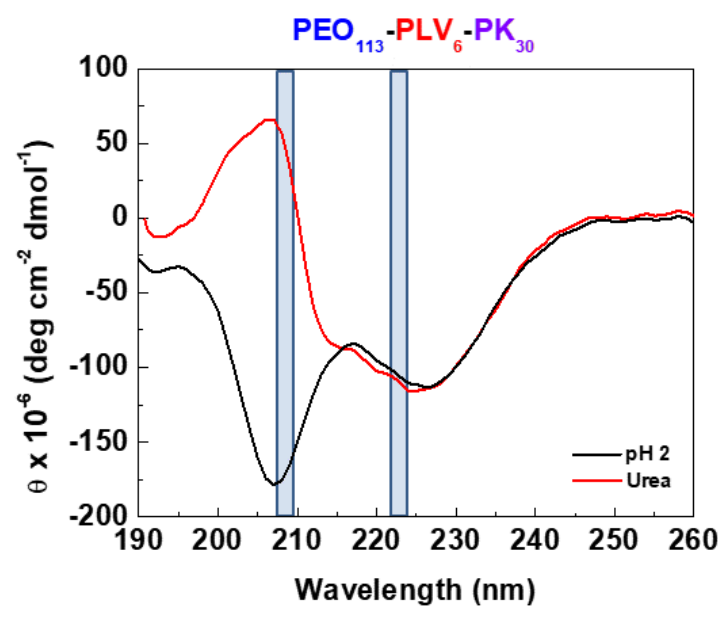

Figure S44. CD Spectra of $\mathrm{PEO}_{113}-\mathrm{PLV}_{6}-\mathrm{PK}_{30}$ at $0.07 \mathrm{wt} \%$ in $5 \mathrm{M}$ Urea solution (red) and $\mathrm{pH} 2$ buffer (black), prepared from a urea co-solvent.

\section{$\underline{\text { TFA Progression Study }}$}

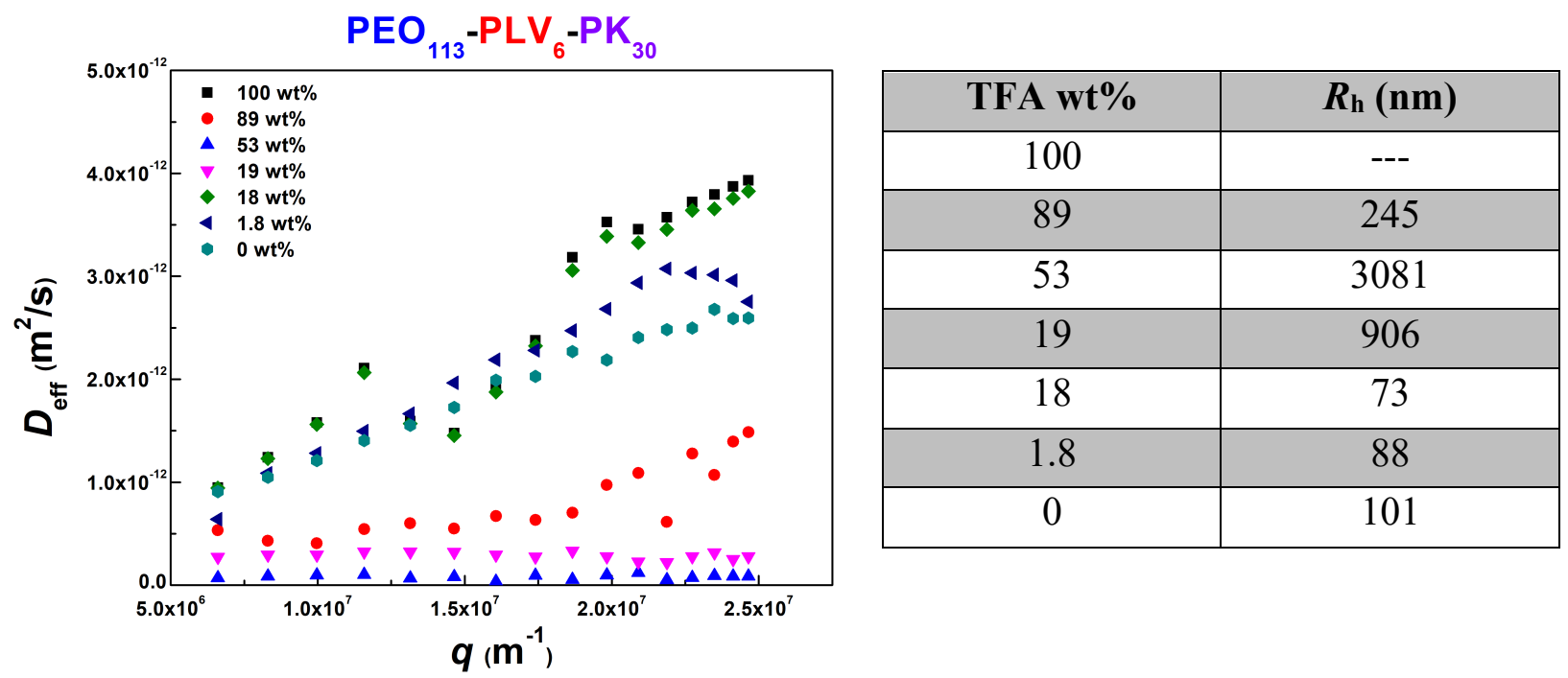

Figure S45. Additional plot of $D_{\text {eff }}$ vs. $q$ for $\mathrm{PEO}_{113}-\mathrm{PLV}_{6}-\mathrm{PK}_{30}$ in $\mathrm{pH} 2$ buffer prepared with a TFA solvent switch, showing good agreement with Figure 7, confirming reproducibility of results. Aliquots were taken to monitor assembly size and angular dependence as a function of TFA wt $\%$. 


\section{Effect of TFE on assembly size}
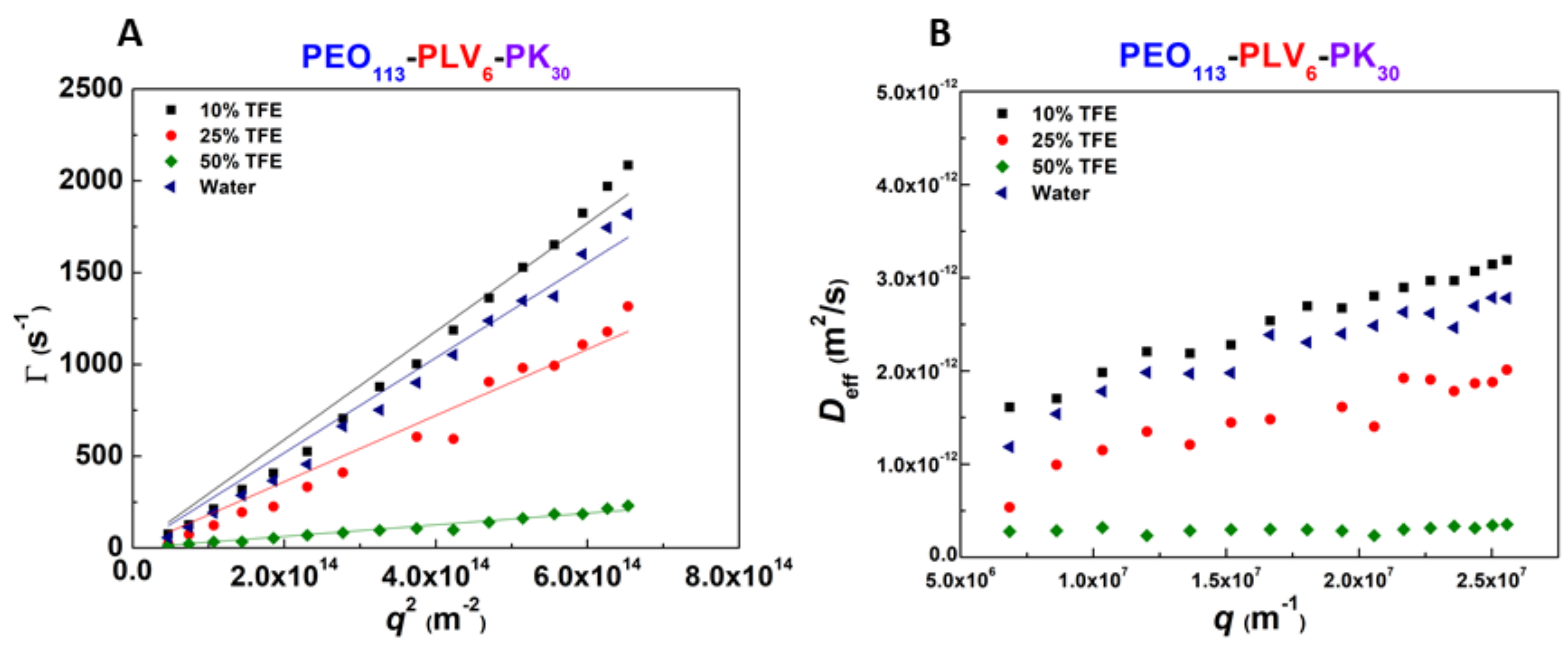

Figure S46. Plots of (A) $\Gamma$ vs. $q^{2}$ and (B) $D_{\text {eff }}$ vs. $q$ for $\mathrm{PEO}_{113}-\mathrm{PLV}_{6}-\mathrm{PK}_{30}$ in $\mathrm{pH} 2$ buffer (blue) with 10\% TFE (black), 25\% TFE (red), and 50\% TFE (green).

\section{$\underline{\text { TFA Refractive Index }}$}

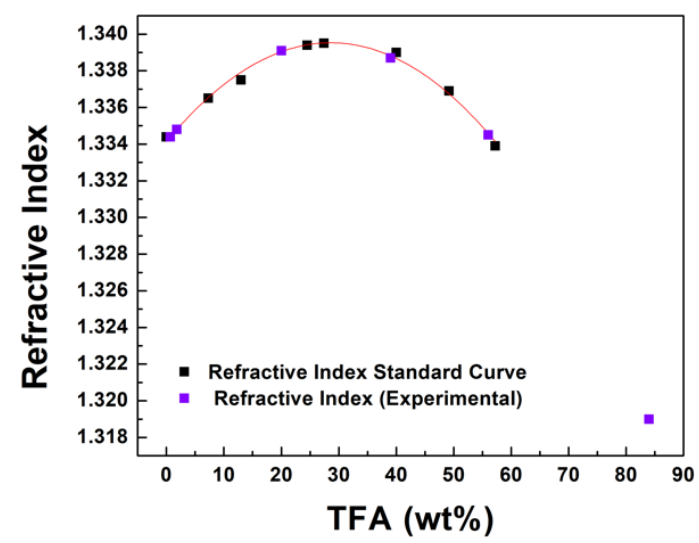

Figure S47. Plot of refractive index vs. TFA concentration. Samples with a known concentration were first used to create a standard curve (black points, red curve). The refractive index of the TFA/water solution was taken periodically during the solvent switch process (purple) to determine TFA concentration. 


\section{$\underline{\text { PEO }}_{113-{ }^{-P L V}}{ }_{48-P K}-K_{40}$ TFA Solvent Switch}
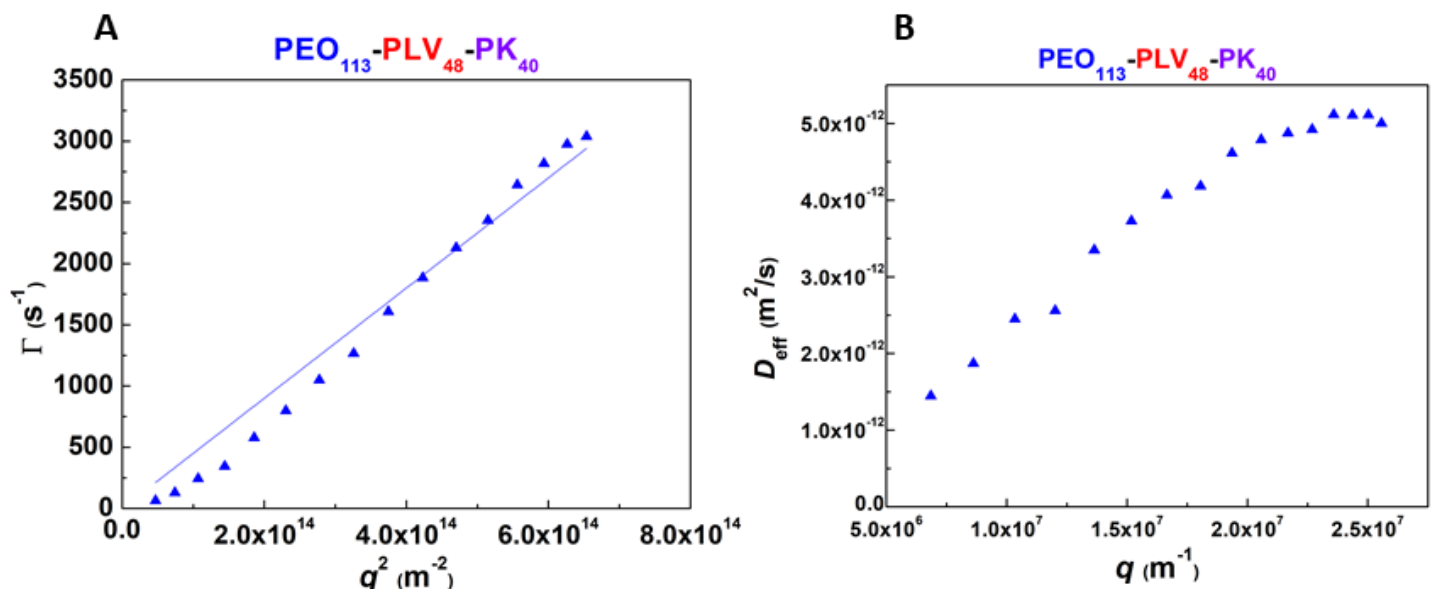

Figure S48. Plots of (A) $\Gamma$ vs. $q^{2}$ and (B) $D_{\text {eff }}$ vs. $q$ for $\mathrm{PEO}_{113}-\mathrm{PLV}_{48}-\mathrm{PK}_{40}$ at $0.05 \mathrm{wt} \%$ in $\mathrm{pH} 2$ buffer prepared from a TFA solvent switch.

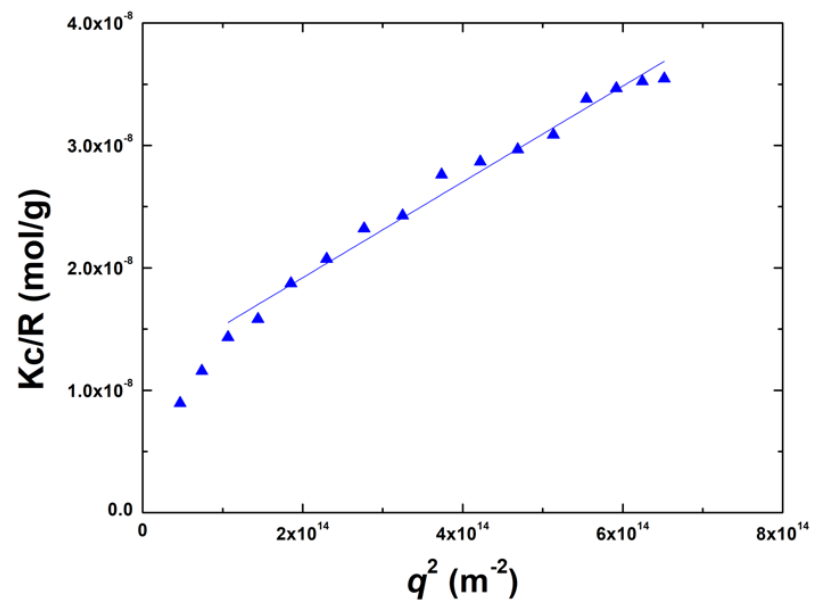

Figure S49. Plot of total scattered intensity vs. $q^{2}$ for $\mathrm{PEO}_{113}-\mathrm{PLV}_{6}-\mathrm{PK}_{30}$ at $0.05 \mathrm{wt} \% \mathrm{pH} 2$ buffer prepared from a TFA solvent switch. 


\section{References}

(1) Yildirim, E.; Dakshinamoorthy, D.; Peretic, M. J.; Pasquinelli, M. A.; Mathers, R. T. Synthetic Design of Polyester Electrolytes Guided by Hydrophobicity Calculations. Macromolecules 2016, 49, 7868.

(2) Belmares, M.; Blanco, M.; Goddard, W. A.; Ross, R. B.; Caldwell, G.; Chou, S.-H.; Pham, J.; Olofson, P. M.; Thomas, C. Hildebrand and Hansen solubility parameters from Molecular Dynamics with applications to electronic nose polymer sensors. J. Comput. Chem. 2004, 25, 1814.

(3) Sun, H. COMPASS: An ab Initio Force-Field Optimized for Condensed-Phase ApplicationsOverview with Details on Alkane and Benzene Compounds. J. Phys. Chem. B. 1998, $102,7338$.

(4) Sun, H.; Jin, Z.; Yang, C. W.; Akkermans, R. L. C.; Robertson, S. H.; Spenley, N. A.; Miller, S.; Todd, S. M. COMPASS II: extended coverage for polymer and drug-like molecule databases. J. Mol. Model. 2016, 22.

(5) Yang, J.; Ren, Y.; Tian, A.-m.; Sun, H. COMPASS Force Field for 14 Inorganic Molecules, He, Ne, $\mathrm{Ar}, \mathrm{Kr}, \mathrm{Xe}, \mathrm{H} 2, \mathrm{O} 2, \mathrm{~N} 2, \mathrm{NO}, \mathrm{CO}, \mathrm{CO} 2, \mathrm{NO} 2, \mathrm{CS} 2$, and SO2, in Liquid Phases. J. Phys. Chem. B 2000, 104, 4951.

(6) Malijevská, I.; Mendlová, V. Density of trifluoroethanoic acid. J. Chem. Thermodyn. 2002, 34, 569. 